\title{
The Migrastatin Family: Discovery of Potent Cell Migration Inhibitors by Chemical Synthesis
}

\author{
Christoph Gaul, ${ }^{\mathrm{a}}$ Jón T. Njardarson, ${ }^{\mathrm{a}}$ Dandan Shan, ${ }^{\mathrm{b}}$ David C. Dorn, ${ }^{\mathrm{c}}$ Kai-Da Wu, ${ }^{\mathrm{c}}$ William P. Tong, ${ }^{\mathrm{d}}$ Xin-Yun \\ Huang, ${ }^{b}$ Malcolm A. S. Moore ${ }^{\mathrm{c}}$ and Samuel J. Danishefsky*,a,e
}

\begin{abstract}
${ }^{a}$ Laboratory for Bioorganic Chemistry, Sloan-Kettering Institute for Cancer Research, 1275 York Avenue, New York, New York 10021, ${ }^{b}$ Department of Physiology, Weill Medical College of Cornell University, 1300 York Avenue, New York, New York 10021, ${ }^{c}$ Laboratory of Developmental Hematopoiesis, Cell Biology Program, Sloan-Kettering Institute for Cancer Research, New York, New York 10021

${ }^{d}$ Analytical Core Facility, Sloan-Kettering Institute for Cancer Research, 1275 York Avenue, New York, New York 10021, ${ }^{e}$ Department of Chemistry, Columbia University, Havemeyer Hall, 3000 Broadway, New York, New York 10027
\end{abstract}

*E-mail:s-danishefsky@ski.mskcc.org

\section{Supporting Information}

Analytical Equipment: Optical rotations were measured on a JASCO DIP-370 digital polarimeter at $\mathrm{rt}$. Concentration $(c)$ in $\mathrm{g} / 100 \mathrm{ml}$ and solvent are given in parentheses. Infrared spectra were obtained on a Perkin-Elmer 1600 FT-IR spectrophotometer neat or as a film in $\mathrm{CHCl}_{3}$ ( $\mathrm{NaCl}$ plates). Absorption bands are noted in $\mathrm{cm}^{-1}$. ${ }^{1} \mathrm{H}$ - and ${ }^{13} \mathrm{C}-\mathrm{NMR}$ spectra were recorded on a Bruker AMX-400 or a Bruker DRX-500 spectrometer in $\mathrm{CDCl}_{3}$. Chemical shifts ( $\delta$-values) are reported in ppm with residual undeuterated $\mathrm{CHCl}_{3}$ as the internal standard (referenced to $7.26 \mathrm{ppm}$ for ${ }^{1} \mathrm{H}-\mathrm{NMR}$ and $77.0 \mathrm{ppm}$ for $\left.{ }^{13} \mathrm{C}-\mathrm{NMR}\right)$. Coupling constants $(J)(\mathrm{H}, \mathrm{H})$ are given in Hz, spectral splitting patterns are designated as singulet (s), doublet (d), triplet (t), quadruplet (q), multiplet or more overlapping signals (m), apparent (app), broad signal (br). Low resolution mass spectra (ionspray, a variation of electrospray) were acquired on a Perkin-Elmer Sciex API 100 spectrometer. Samples were introduced by direct infusion. High resolution mass spectra (fast atom bombardment, FAB) were acquired on a Micromass 70-SE-4F spectrometer. Flash chromatography (FC) was performed with E. Merck silica gel (60, particle size 0.040-0.063 $\mathrm{mm}$ ). Preparative thin layer chromatography (TLC) was performed with Whatman Partisil Plates $(10 \times 10 \mathrm{~cm}, 60 \AA, 200 \mu \mathrm{m})$.

Techniques, Solvents, and Reagents: Reactions involving air or moisture-sensitive reagents or intermediates were performed under argon or nitrogen atmosphere in glassware which had been heat gun or flame-dried under high vacuum. Indicated reaction temperatures refer to those of the reaction bath, while room temperature (rt) is noted as $22{ }^{\circ} \mathrm{C}$. Preparative reactions were stirred magnetically. Tetrahydrofuran (THF), diethyl ether $\left(\mathrm{Et}_{2} \mathrm{O}\right)$, methylene chloride $\left(\mathrm{CH}_{2} \mathrm{Cl}_{2}\right)$, and toluene were obtained from a dry solvent system (activated alumina columns, positive pressure of argon). All other solvents were used as received in Sure/Seal bottles (Aldrich). Triethylamine 
$\left(\mathrm{Et}_{3} \mathrm{~N}\right)$, diisopropylethylamine $\left(i-\mathrm{Pr}_{2} \mathrm{NEt}\right)$, pyridine, 2,6-lutidine, and chlorotrimethylsilane (TMSCl) were distilled from $\mathrm{CaH}_{2}$ immediately prior to use. All other reagents were purchased from Aldrich at the highest commercial quality and used without further purification, with the exception of the Stryker reagent which was purchased from Fluka, the RCM catalysts $\mathbf{1 6}$ and $\mathbf{1 7}$ which were purchased from Strem, and biotin- $\mathrm{dPEG}_{4}$-hydrazide which was purchased from Quanta Biodesign.

Vinyl Carbinol 19: Compound 19 was prepared using a slightly modified literature procedure by Madsen. ${ }^{1}$

Preparation of the divinylzinc reagent: To vinylmagnesium bromide $(294 \mathrm{~mL}, 294 \mathrm{mmol}, 1.0 \mathrm{M}$ in THF) was added slowly a solution of anhydrous $\mathrm{ZnCl}_{2}$ (20.0 g, $147 \mathrm{mmol}$, beads) in THF (100 $\mathrm{mL}$ ) to yield a dark brown solution of divinylzinc in THF (with some precipitate).

Preparation of vinyl carbinol 19: To a solution of dimethyl 2,3- $O$-isopropylidene-L-tartrate 18 $(8.58 \mathrm{~g}, 39.3 \mathrm{mmol})$ in toluene $(100 \mathrm{~mL})$ at $-78{ }^{\circ} \mathrm{C}$ was added slowly DIBALH $(90 \mathrm{~mL}, 90.0$ $\mathrm{mmol}, 1.0 \mathrm{M}$ in toluene). The reaction mixture turned into a white slurry during the course of the addition. After stirring for $3 \mathrm{~h}$ (the reaction temperature has to be kept at $-78{ }^{\circ} \mathrm{C}$ to prevent overreduction), the divinylzinc solution as prepared above was added to the reaction mixture via cannula over $45 \mathrm{~min}$. After stirring for another $30 \mathrm{~min}$, the reaction mixture was warmed to $\mathrm{rt}$ and stirred for $4 \mathrm{~h}$. The reaction mixture was then carefully (!) treated with saturated aqueous $\mathrm{NH}_{4} \mathrm{Cl}$ solution and $20 \%$ aqueous $\mathrm{Na} / \mathrm{K}$-tartrate solution. The organic layer was separated and the aqueous layer was extracted with $\mathrm{Et}_{2} \mathrm{O}(3 \mathrm{x})$. The combined organic layers were dried $\left(\mathrm{MgSO}_{4}\right)$ and concentrated under reduced pressure. Purification of the crude product by FC (hexane/EtOAc 4:1) afforded vinyl carbinol $19(6.28 \mathrm{~g}, 75 \%$, diastereoselectivity $>90 \%)$ as a colorless oil. ${ }^{1} \mathrm{H}-\mathrm{NMR}\left(400 \mathrm{MHz}, \mathrm{CDCl}_{3}\right) \delta 6.04-5.94(\mathrm{~m}, 2 \mathrm{H}), 5.40(\mathrm{~d}, J=17.3,2 \mathrm{H}), 5.30$ (d, $J$ $=10.5,2 \mathrm{H}), 4.19-4.16(\mathrm{~m}, 2 \mathrm{H}), 3.89-3.87(\mathrm{~m}, 2 \mathrm{H}), 2.91(\mathrm{br} \mathrm{s}, 2 \mathrm{H}), 1.42(\mathrm{~s}, 6 \mathrm{H})$.

1,2-Diol 20: The preparation of compound 20 has been reported before by Chang, ${ }^{2}$ but experimental details have not been provided.

To a solution of vinyl carbinol $19(6.28 \mathrm{~g}, 29.2 \mathrm{mmol})$ in DMF $(100 \mathrm{~mL})$ at $0{ }^{\circ} \mathrm{C}$ was added $\mathrm{NaH}$ (2.58 g, $64.5 \mathrm{mmol}, 60 \%$ dispersion in mineral oil) and, 5 min later, MeI (4.38 mL, $70.3 \mathrm{mmol})$. The reaction mixture was warmed to rt, stirred for $45 \mathrm{~min}$, and then treated with $2 \mathrm{M} \mathrm{NH}_{4} \mathrm{OH}$. The organic layer was separated and the aqueous layer was extracted with $\mathrm{Et}_{2} \mathrm{O}(3 \mathrm{x})$. The combined organic layers were dried $\left(\mathrm{MgSO}_{4}\right)$ and concentrated under reduced pressure. The crude product was dissolved in $\mathrm{MeOH}(150 \mathrm{~mL})$ and $2 \mathrm{M} \mathrm{HCl}(50 \mathrm{~mL})$ and heated to reflux for 2

\footnotetext{
${ }^{1}$ Jorgensen, M.; Iversen, E. H.; Paulsen, A. L.; Madsen, R. J. Org. Chem. 2001, 66, 4630.

${ }^{2}$ Lee, W. W.; Chang, S. Tetrahedron: Asymmetry 1999, 10, 4473.
} 
h. The reaction mixture was cooled to $\mathrm{rt}$, treated with saturated aqueous $\mathrm{Na}_{2} \mathrm{CO}_{3}$ solution and diluted with $\mathrm{Et}_{2} \mathrm{O}$. The organic layer was separated and the aqueous layer was extracted with $\mathrm{Et}_{2} \mathrm{O}(3 \mathrm{x})$. The combined organic layers were dried $\left(\mathrm{MgSO}_{4}\right)$ and concentrated under reduced pressure. Purification of the crude product by FC (hexane/EtOAc 2:1) afforded 1,2-diol 20 (4.72 g, 80\%) as a colorless oil. $[\alpha]_{\mathrm{D}}+31.0^{\circ}\left(c 1.77, \mathrm{CHCl}_{3}\right)$; IR (neat) $3454,3078,2982,2936,2824$, 1643, 1420, 1192, 1102, 992; ${ }^{1} \mathrm{H}-\mathrm{NMR}\left(500 \mathrm{MHz}, \mathrm{CDCl}_{3}\right) \delta$ 5.77-5.71 (m, 2H), 5.36-5.32 (m, 4H), 3.81 (app t, $J=6.3,2 \mathrm{H}), 3.76(\mathrm{~d}, J=5.5,2 \mathrm{H}), 3.32(\mathrm{~s}, 6 \mathrm{H}), 2.96(\mathrm{br} \mathrm{s}, 2 \mathrm{H}) ;{ }^{13} \mathrm{C}-\mathrm{NMR}(125$

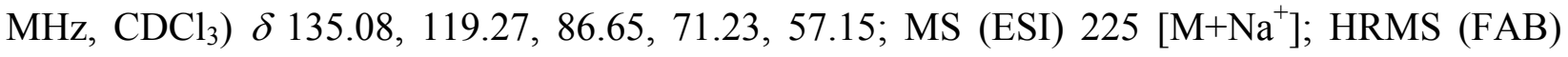
calcd. for $\mathrm{C}_{10} \mathrm{H}_{18} \mathrm{O}_{4} \mathrm{Na}\left[\mathrm{M}+\mathrm{Na}^{+}\right]$225.1103, found 225.1079.

Butadiene 3: Compound 3 was prepared using modified literature procedures. ${ }^{3}$

To a suspension of $\mathrm{NaH}(4.40 \mathrm{~g}, 110 \mathrm{mmol}, 60 \%$ dispersion in mineral oil) in toluene $(90 \mathrm{~mL})$ and $\mathrm{MeOH}(0.1 \mathrm{~mL})$ at $0{ }^{\circ} \mathrm{C}$ was added a mixture of 3-pentanone $(10.6 \mathrm{~mL}, 105 \mathrm{mmol})$ and methyl formate $(8.00 \mathrm{~mL}, 130 \mathrm{mmol})$ over $1 \mathrm{hr}$. The reaction mixture was warmed to rt, stirred for another $3 \mathrm{~h}$, and then diluted with $\mathrm{Et}_{2} \mathrm{O}$. The suspension was filtered and the precipitate was washed with $\mathrm{Et}_{2} \mathrm{O}$. The resulting crude sodium salt of 1-hydroxy-2-methyl-1-penten-3-one was dissolved in DMSO $(100 \mathrm{~mL})$ and $\mathrm{Me}_{2} \mathrm{SO}_{4}(9.16 \mathrm{~mL}, 97.0 \mathrm{mmol})$ was added at rt. After stirring for $30 \mathrm{~min}$, the reaction mixture was treated with $2 \mathrm{M} \mathrm{NH}_{4} \mathrm{OH}$ and diluted with $\mathrm{Et}_{2} \mathrm{O}$. The organic layer was separated, washed with $\mathrm{H}_{2} \mathrm{O}$ and saturated aqueous $\mathrm{NaCl}$ solution, dried $\left(\mathrm{MgSO}_{4}\right)$, and concentrated under reduced pressure to afford 1-methoxy-2-methyl-1-penten-3-one $(8.27 \mathrm{~g}$, 74\%). To a solution of 1-methoxy-2-methyl-1-penten-3-one (2.60 g, $20.3 \mathrm{mmol})$ in $\mathrm{Et}_{2} \mathrm{O}(12.0$ $\mathrm{mL})$ was added $\mathrm{Et}_{3} \mathrm{~N}(7.08 \mathrm{~mL}, 50.8 \mathrm{mmol})$ and TMSOTf $(3.68 \mathrm{~mL}, 20.3 \mathrm{~mL})$ at $0{ }^{\circ} \mathrm{C}$. The reaction mixture was warmed to $\mathrm{rt}$, stirred for another $3 \mathrm{~h}$, and then poured onto a saturated aqueous $\mathrm{NaHCO}_{3}$ solution. The organic layer was separated, washed with saturated aqueous $\mathrm{NaCl}$ solution, dried $\left(\mathrm{MgSO}_{4}\right)$, and concentrated under reduced pressure to afford butadiene 3 (3.66 g, 90\%). ${ }^{1} \mathrm{H}-\mathrm{NMR}\left(400 \mathrm{MHz}, \mathrm{CDCl}_{3}\right) \delta 6.35(\mathrm{~s}, 1 \mathrm{H}), 4.75(\mathrm{q}, J=6.9,1 \mathrm{H}), 3.63(\mathrm{~s}, 3 \mathrm{H})$, $1.66(\mathrm{~s}, 3 \mathrm{H}), 1.62(\mathrm{~d}, J=6.9,3 \mathrm{H}), 0.22(\mathrm{~s}, 9 \mathrm{H})$.

Dihydropyrone 21: To a solution of diol $20(2.55 \mathrm{~g}, 12.6 \mathrm{mmol})$ in $\mathrm{CH}_{2} \mathrm{Cl}_{2}(130 \mathrm{~mL})$ at $0{ }^{\circ} \mathrm{C}$ was added $\mathrm{Na}_{2} \mathrm{CO}_{3}(1.40 \mathrm{~g}, 13.2 \mathrm{mmol})$ and $\mathrm{Pb}(\mathrm{OAc})_{4}(5.87 \mathrm{~g}, 13.2 \mathrm{mmol})$. The reaction mixture was warmed to rt, stirred for $25 \mathrm{~min}$, and then treated with ethylene glycol $(300 \mu \mathrm{L})$. After stirring for another $5 \mathrm{~min}$, the reaction mixture was filtered through a Celite pad. The filtrate was washed with saturated aqueous $\mathrm{NaHCO}_{3}$ solution and saturated aqueous $\mathrm{NaCl}$ solution and dried

\footnotetext{
${ }^{3}$ Danishefsky, S. J.; Yan, C. F.; Singh, R. K.; Gammill, R. B.; McCurry Jr., P. M.; Fritsch, N.; Clardy, J. J. Am. Chem. Soc. 1979, 101, 7001.
} 
$\left(\mathrm{MgSO}_{4}\right)$. The obtained solution of $\alpha$-methoxy- $\alpha$-vinyl aldehyde 2 in $\mathrm{CH}_{2} \mathrm{Cl}_{2}$ was cooled to -78 ${ }^{\circ} \mathrm{C}$, and then $\mathrm{TiCl}_{4}(2.77 \mathrm{~mL}, 25.2 \mathrm{mmol})$ and butadiene $3(6.06 \mathrm{~g}, 30.3 \mathrm{mmol})$ were added. After stirring for $20 \mathrm{~min}$, the reaction mixture was treated with $\mathrm{MeOH}(5 \mathrm{~min})$, followed by the addition of saturated aqueous $\mathrm{NaHCO}_{3}$ solution and $20 \%$ aqueous $\mathrm{Na} / \mathrm{K}$-tartrate solution. The organic layer was separated and the aqueous layer was extracted with $\mathrm{CH}_{2} \mathrm{Cl}_{2}(3 \mathrm{x})$. The combined organic layers were dried $\left(\mathrm{MgSO}_{4}\right)$ and concentrated under reduced pressure. The crude product was dissolved in $\mathrm{CH}_{2} \mathrm{Cl}_{2}(130 \mathrm{~mL})$ and TFA $(13 \mathrm{~mL})$ and stirred for $1 \mathrm{hr}$. Toluene $(50 \mathrm{~mL})$ was added and the reaction mixture was concentrated under reduced pressure. Purification of the crude product by FC (hexane/EtOAc 20:1 $\rightarrow$ 10:1 $\rightarrow$ 7:1) afforded dihydropyrone $21(4.31 \mathrm{~g}, 87 \%)$ as a colorless oil. $\left.[\alpha]_{\mathrm{D}}+77.1^{\circ}(c) 2.00, \mathrm{CHCl}_{3}\right)$; IR (neat) 2980, 2938, 2883, 2827, 1785, 1671, 1622, 1602, 1460, 1387, 1305, 1214, 1176, 1085, 1010; ${ }^{1} \mathrm{H}-\mathrm{NMR}$ $\left(500 \mathrm{MHz}, \mathrm{CDCl}_{3}\right) \delta 7.36(\mathrm{~s}, 1 \mathrm{H}), 5.63-5.54(\mathrm{~m}, 1 \mathrm{H}), 5.48-5.43(\mathrm{~m}, 2 \mathrm{H}), 4.25(\mathrm{dd}, J=8.6,2.9$, 1H), 3.88 (app t, $J=8.5,1 \mathrm{H}), 3.37$ (s, 3H), 2.44 (dq, $J=7.2,2.9,1 \mathrm{H}), 1.68$ (s, 3H), 1.07 (d, $J=$ 7.2, 3H); ${ }^{13} \mathrm{C}-\mathrm{NMR}\left(125 \mathrm{MHz}, \mathrm{CDCl}_{3}\right) \delta 198.99,160.75,131.79,122.06,112.51,82.69,81.99$, 56.37, 40.62, 10.42, 9.96; MS (ESI) $219\left[\mathrm{M}+\mathrm{Na}^{+}\right]$; HRMS (FAB) calcd. for $\mathrm{C}_{11} \mathrm{H}_{16} \mathrm{O}_{3} \mathrm{Na}$ $\left[\mathrm{M}+\mathrm{Na}^{+}\right]$219.0997, found 219.0991.

Diol 25: To a solution of dihydropyrone $21(4.30 \mathrm{~g}, 21.9 \mathrm{mmol})$ in THF $(50 \mathrm{~mL})$ at $-10{ }^{\circ} \mathrm{C}$ was added $\mathrm{MeOH}(977 \mu \mathrm{L}, 24.1 \mathrm{mmol})$ and $\mathrm{LiBH}_{4}(12.1 \mathrm{~mL}, 24.1 \mathrm{mmol}, 2 \mathrm{M}$ in THF). After stirring for $10 \mathrm{~min}$, the reaction mixture was carefully treated with $0.2 \mathrm{M} \mathrm{HCl}(25 \mathrm{~mL})$ and stirring was continued for another $20 \mathrm{~min}$. Then the organic layer was separated and the aqueous layer was extracted with EtOAc (4x). The combined organic layers were dried $\left(\mathrm{MgSO}_{4}\right)$ and concentrated under reduced pressure. The crude alcohol 22 was dissolved in THF $(280 \mathrm{~mL})$ and $\mathrm{H}_{2} \mathrm{O}(28 \mathrm{~mL})$, and champhorsulfonic acid (1.02 g, $4.38 \mathrm{mmol})$ was added. After refluxing for $2 \mathrm{~h}$, the reaction mixture was treated with saturated aqueous $\mathrm{NaHCO}_{3}$ solution. The organic layer was separated and the aqueous layer was extracted with EtOAc (3x). The combined organic layers were dried $\left(\mathrm{MgSO}_{4}\right)$ and concentrated under reduced pressure. The crude lactol $\mathbf{2 3}$ was dissolved in THF $(60 \mathrm{~mL})$ and $\mathrm{H}_{2} \mathrm{O}(15 \mathrm{~mL})$, and $\mathrm{LiBH}_{4}(12.1 \mathrm{~mL}, 24.1 \mathrm{mmol}, 2 \mathrm{M}$ in THF) was added at rt. After stirring for $15 \mathrm{~min}$, the reaction mixture was treated with $0.2 \mathrm{M} \mathrm{HCl}(35 \mathrm{~mL})$ and stirring was continued for another $20 \mathrm{~min}$. Then the organic layer was separated and the aqueous layer was extracted with EtOAc (3x). The combined organic layers were dried $\left(\mathrm{MgSO}_{4}\right)$ and concentrated under reduced pressure. Purification of the crude product by FC (hexane/EtOAc 4:1 $\rightarrow$ 2:1 $\rightarrow$ 1:1) afforded diol $25(2.34 \mathrm{~g}, 53 \%)$ as a colorless oil. $[\alpha]_{\mathrm{D}}+40.0^{\circ}\left(c 1.00, \mathrm{CHCl}_{3}\right)$; IR $\left(\mathrm{CHCl}_{3}\right)$ $3621,3565,3444,3012,2934,2868,1449,1393,1238,1083 ;{ }^{1} \mathrm{H}-\mathrm{NMR}\left(500 \mathrm{MHz}, \mathrm{CDCl}_{3}\right) \delta$ $5.74-5.67(\mathrm{~m}, 1 \mathrm{H}), 5.33-5.25(\mathrm{~m}, 2 \mathrm{H}), 5.16(\mathrm{~d}, J=10.2,1 \mathrm{H}), 4.12(\mathrm{~d}, J=11.9,1 \mathrm{H}), 3.95(\mathrm{~d}, J=$ $11.9,1 \mathrm{H}), 3.48$ (dd, $J=8.1,5.4,1 \mathrm{H}), 3.26(\operatorname{app} \mathrm{t}, J=5.5,1 \mathrm{H}), 3.23(\mathrm{~s}, 3 \mathrm{H}), 2.74-2.68(\mathrm{~m}, 1 \mathrm{H})$, 
2.57 (br s, 2H), $1.79(\mathrm{~d}, J=1.4,3 \mathrm{H}), 0.98(\mathrm{~d}, J=6.9,3 \mathrm{H}) ;{ }^{13} \mathrm{C}-\mathrm{NMR}\left(125 \mathrm{MHz}, \mathrm{CDCl}_{3}\right) \delta$ 135.32, 135.20, 130.41, 119.51, 83.42, 77.44, 61.51, 55.93, 34.80, 21.89, 16.85; MS (ESI) 223 $\left[\mathrm{M}+\mathrm{Na}^{+}\right]$; HRMS (FAB) calcd. for $\mathrm{C}_{11} \mathrm{H}_{20} \mathrm{O}_{3} \mathrm{Na}\left[\mathrm{M}+\mathrm{Na}^{+}\right] 223.1310$, found 223.1301.

Dimeric Acetal 24: The Ferrier rearrangement described above was carried out at a concentration of $0.07 \mathrm{M}$. When the Ferrier rearrangement was conducted at a concentration of $0.30 \mathrm{M}$, the formation of a side product, which corresponds to dimeric acetal 24, was observed. Compound 24 was isolated after FC (hexane/EtOAc 20:1 $\rightarrow$ 10:1) in 15-20\% yield as a white crystalline solid. M.p. 83-85 ${ }^{\circ} \mathrm{C}$; $[\alpha]_{\mathrm{D}}-161.3^{\circ}$ (c 1.00, $\left.\mathrm{CHCl}_{3}\right)$; IR $\left(\mathrm{CHCl}_{3}\right)$ 3003, 2910, 2816, 1446, 1382, 1317, 1211, 1088, 965; ${ }^{1} \mathrm{H}-\mathrm{NMR}\left(500 \mathrm{MHz}, \mathrm{CDCl}_{3}\right) \delta 5.67-5.59$ (m, 4H), 5.39-5.28 (m, 6H), 3.93 (dd, $J=8.4,2.9,2 \mathrm{H}), 3.57$ (app t, $J=8.2,2 \mathrm{H}), 3.32$ (s, 6H), 1.94-1.91 (m, 2H), $1.74(\mathrm{~s}, 6 \mathrm{H}), 0.91(\mathrm{~d}, J=6.8,6 \mathrm{H}) ;{ }^{13} \mathrm{C}-\mathrm{NMR}\left(125 \mathrm{MHz}, \mathrm{CDCl}_{3}\right) \delta 134.66,132.01,129.40$, 119.11, 93.37, 83.15, 72.19, 56.79, 30.44, 18.81, 12.78; MS (ESI) 401 [M+Na ${ }^{+}$; HRMS (FAB) calcd. for $\mathrm{C}_{22} \mathrm{H}_{35} \mathrm{O}_{5}\left[\mathrm{M}+\mathrm{H}^{+}\right] 379.2485$, found 379.2486 .

Monoprotected Diol 26: To a solution of diol 25 (364 mg, $1.82 \mathrm{mmol})$ in $\mathrm{CH}_{2} \mathrm{Cl}_{2}(8 \mathrm{~mL})$ at $\mathrm{rt}$ was added 2,6-lutidine $(530 \mu \mathrm{L}, 4.55 \mathrm{mmol})$ and TBSOTf $(961 \mu \mathrm{L}, 4.19 \mathrm{mmol})$. After stirring for $20 \mathrm{~min}$, the reaction mixture was treated with saturated aqueous $\mathrm{NaHCO}_{3}$ solution. The organic layer was separated and the aqueous layer was extracted with $\mathrm{CH}_{2} \mathrm{Cl}_{2}(3 \mathrm{x})$. The combined organic layers were dried $\left(\mathrm{MgSO}_{4}\right)$ and concentrated under reduced pressure. Purification of the crude product by FC (hexane/EtOAc 30:1) afforded the corresponding diprotected diol $(731 \mathrm{mg}, 94 \%)$ as a colorless oil. $[\alpha]_{\mathrm{D}}+0.1^{\circ}\left(c 1.00, \mathrm{CHCl}_{3}\right)$; IR $\left(\mathrm{CHCl}_{3}\right) 2929$, 2856, 1472, 1253, 1076; ${ }^{1} \mathrm{H}-\mathrm{NMR}\left(500 \mathrm{MHz}, \mathrm{CDCl}_{3}\right) \delta 5.67-5.60(\mathrm{~m}, 1 \mathrm{H}), 5.29-5.21(\mathrm{~m}, 3 \mathrm{H})$, $4.14(\mathrm{~d}, J=11.8,1 \mathrm{H}), 4.04(\mathrm{~d}, J=11.8,1 \mathrm{H}), 3.43(\mathrm{dd}, J=7.2,2.9,1 \mathrm{H}), 3.37$ (app t, $J=7.5$, $1 \mathrm{H}), 3.21(\mathrm{~s}, 3 \mathrm{H}), 2.60-2.56(\mathrm{~m}, 1 \mathrm{H}), 1.72(\mathrm{~d}, J=0.9,3 \mathrm{H}), 0.91-0.89(\mathrm{~m}, 21 \mathrm{H}), 0.05-0.04(\mathrm{~m}$, $12 \mathrm{H}) ;{ }^{13} \mathrm{C}-\mathrm{NMR}\left(125 \mathrm{MHz}, \mathrm{CDCl}_{3}\right) \delta 135.44,133.27,131.41,118.43,86.20,78.68,61.91,56.17$, $33.85,26.17,25.93,20.99,18.56,18.36,14.13,-3.82,-4.80,-5.29$; MS (ESI) $451\left[\mathrm{M}+\mathrm{Na}^{+}\right]$; HRMS (FAB) calcd. for $\mathrm{C}_{23} \mathrm{H}_{48} \mathrm{O}_{3} \mathrm{Si}_{2} \mathrm{Na}\left[\mathrm{M}+\mathrm{Na}^{+}\right]$451.3040, found 451.3054.

A solution of the diprotected diol $(731 \mathrm{mg}, 1.71 \mathrm{mmol})$ in $\mathrm{HOAc}(9 \mathrm{~mL})$, THF $(3 \mathrm{~mL})$, and $\mathrm{H}_{2} \mathrm{O}$ $(3 \mathrm{~mL})$ was stirred at $\mathrm{rt}$ for $8 \mathrm{~h}$. The reaction mixture was neutralized with solid $\mathrm{Na}_{2} \mathrm{CO}_{3}$ and diluted with $\mathrm{H}_{2} \mathrm{O}$ and $\mathrm{Et}_{2} \mathrm{O}$. The organic layer was separated and the aqueous layer was extracted with $\mathrm{Et}_{2} \mathrm{O}(3 \mathrm{x})$. The combined organic layers were dried $\left(\mathrm{MgSO}_{4}\right)$ and concentrated under reduced pressure. Purification of the crude product by FC (hexane/EtOAc 10:1 $\rightarrow$ 5:1) afforded monoprotected diol $26(456 \mathrm{mg}, 85 \%)$ as a colorless oil. $[\alpha]_{\mathrm{D}}+3.8^{\circ}\left(c 1.85, \mathrm{CHCl}_{3}\right)$; IR (neat) 3352, 2957, 2930, 2857, 1472, 1462, 1250, 1127, 1081, 1028; ${ }^{1} \mathrm{H}-\mathrm{NMR}\left(500 \mathrm{MHz}, \mathrm{CDCl}_{3}\right) \delta$ 5.73-5.66 (m, 1H), 5.30-5.24 (m, 3H), $4.12(\mathrm{dd}, J=11.8,4.9,1 \mathrm{H}), 4.00(\mathrm{dd}, J=11.8,6.5,1 \mathrm{H})$, 
3.48-3.43 (m, 2H), $3.22(\mathrm{~s}, 3 \mathrm{H}), 2.69-2.61(\mathrm{~m}, 1 \mathrm{H}), 1.78(\mathrm{~d}, J=1.1,3 \mathrm{H}), 1.68$ (br t, $1 \mathrm{H}), 0.90-$ $0.89(\mathrm{~m}, 12 \mathrm{H}), 0.06(\mathrm{~s}, 3 \mathrm{H}), 0.04(\mathrm{~s}, 3 \mathrm{H}) ;{ }^{13} \mathrm{C}-\mathrm{NMR}\left(125 \mathrm{MHz}, \mathrm{CDCl}_{3}\right) \delta 135.15,133.05,118.54$, 85.89, 78.28, 61.76, 56.12, 34.23, 26.11, 25.64, 21.53, 18.49, 15.32, -3.88, -4.70; MS (ESI) 337 $\left[\mathrm{M}+\mathrm{Na}^{+}\right]$; HRMS (FAB) calcd. for $\mathrm{C}_{17} \mathrm{H}_{34} \mathrm{O}_{3} \mathrm{SiNa}\left[\mathrm{M}+\mathrm{Na}^{+}\right]$337.2175, found 337.2162.

Propionyl Oxazolidinone 28: Compound 28 was prepared by reaction of $(R)-(+)-4$-benzyl-2oxazolidinone with BuLi and propionyl chloride in THF according to standard literature procedures. $^{4}$

Aldol Product 29: To a solution of alcohol 26 (189 mg, $0.601 \mathrm{mmol})$ in $\mathrm{CH}_{2} \mathrm{Cl}_{2}$ (4 mL) at rt was added Dess-Martin periodinane $(280 \mathrm{mg}, 0.661 \mathrm{mmol})$. After stirring for $50 \mathrm{~min}$, the reaction mixture was treated with saturated aqueous $\mathrm{Na}_{2} \mathrm{~S}_{2} \mathrm{O}_{3}$ solution and saturated aqueous $\mathrm{NaHCO}_{3}$ solution. The organic layer was separated and the aqueous layer was extracted with $\mathrm{CH}_{2} \mathrm{Cl}_{2}(3 \mathrm{x})$. The combined organic layers were dried $\left(\mathrm{MgSO}_{4}\right)$ and concentrated under reduced pressure to yield crude aldehyde 27. IR (neat) 2958, 2936, 2891, 2858, 1674, 1467, 1378, 1249, 1126, 1093, 1031; ${ }^{1} \mathrm{H}-\mathrm{NMR}\left(500 \mathrm{MHz}, \mathrm{CDCl}_{3}\right) \delta 10.06(\mathrm{~s}, 1 \mathrm{H}), 6.51$ (dd, $\left.J=10.7,1.5,1 \mathrm{H}\right), 5.63(\mathrm{ddd}, J=$ $17.4,10.5,7.9,1 \mathrm{H}), 5.32-5.25(\mathrm{~m}, 2 \mathrm{H}), 3.56(\mathrm{dd}, J=6.6,3.8,1 \mathrm{H}), 3.45($ app t, $J=7.3,1 \mathrm{H}), 3.42-$ $3.35(\mathrm{~m}, 1 \mathrm{H}), 3.20(\mathrm{~s}, 3 \mathrm{H}), 1.75(\mathrm{~s}, 3 \mathrm{H}), 1.03(\mathrm{~d}, J=6.6,3 \mathrm{H}), 0.91(\mathrm{~s}, 9 \mathrm{H}), 0.07(\mathrm{~s}, 3 \mathrm{H}), 0.02(\mathrm{~s}$, $3 \mathrm{H}) ;{ }^{13} \mathrm{C}-\mathrm{NMR}\left(125 \mathrm{MHz}, \mathrm{CDCl}_{3}\right) \delta 191.36,153.37,134.76,133.96,119.12,85.73,78.03,56.21$, $33.15,26.05,18.44,16.37,14.73,-3.84,-4.85$.

The crude aldehyde 27 was dissolved in EtOAc $(2 \mathrm{~mL})$ and added to neat propionyl oxazolidinone $28(210 \mathrm{mg}, 0.902 \mathrm{mmol})$. The reaction mixture was then treated at $\mathrm{rt}$ with anhydrous $\mathrm{MgCl}_{2}(57 \mathrm{mg}, 0.601 \mathrm{mmol}), \mathrm{Et}_{3} \mathrm{~N}(210 \mu \mathrm{L}, 1.50 \mathrm{mmol})$, and $\mathrm{TMSCl}(153 \mu \mathrm{L}, 1.20$ $\mathrm{mmol})$. After stirring for $36 \mathrm{~h}$, the reaction mixture was filtered through a silica plug $\left(\mathrm{Et}_{2} \mathrm{O}\right)$ and the filtrate was concentrated under reduced pressure. The residual oil was dissolved in $\mathrm{MeOH}(3$ $\mathrm{mL})$, treated with TFA (1 drop) and stirred for $10 \mathrm{~min}$. Toluene $(3 \mathrm{~mL})$ was added and the reaction mixture was concentrated under reduced pressure. Purification of the crude product by FC (hexane/ $\mathrm{CH}_{2} \mathrm{Cl}_{2}$ 1:1 $\rightarrow \mathrm{CH}_{2} \mathrm{Cl}_{2}$ ) afforded aldol product 29 (219 mg, 67\%) as a colorless oil. $[\alpha]_{\mathrm{D}}-16.1^{\circ}\left(c 1.77, \mathrm{CHCl}_{3}\right)$; IR (neat) 3505, 2920, 2856, 1782, 1699, 1453, 1384, 1258, 1208, 1125, 1079, 1020; ${ }^{1} \mathrm{H}-\mathrm{NMR}\left(500 \mathrm{MHz}, \mathrm{CDCl}_{3}\right) \delta 7.35-7.26(\mathrm{~m}, 5 \mathrm{H}), 5.64(\mathrm{ddd}, J=17.6,10.3$, 7.6, 1H), $5.56(\mathrm{~d}, J=10.2,1 \mathrm{H}), 5.37$ (dd, $J=10.4,1.8,1 \mathrm{H}), 5.30(\mathrm{dd}, J=17.4,1.8,1 \mathrm{H}), 4.73-$ 4.69 (m, 2H), 4.22-4.16 (m, 2H), 4.14-4.08 (m, 1H), 3.46 (dd, $J=8.0,1.8,1 \mathrm{H}), 3.39$ (app t, $J=$ 8.0, 1H), $3.36(\mathrm{dd}, J=14.1,3.8,1 \mathrm{H}), 3.21(\mathrm{~s}, 3 \mathrm{H}), 2.81$ (dd, $J=13.6,9.6,1 \mathrm{H}), 2.75-2.68$ (m, 1H), 2.39 (br s, 1H), 1.75 (s, 3H), 1.02 (d, $J=7.0,3 \mathrm{H}), 0.92(\mathrm{~s}, 9 \mathrm{H}), 0.91$ (d, $J=6.0,3 \mathrm{H}), 0.07$

\footnotetext{
${ }^{4}$ Evans, D. A. Aldrichimica Acta 1982, 15, 23.
} 
(s, 3H), $0.04(\mathrm{~s}, 3 \mathrm{H}) ;{ }^{13} \mathrm{C}-\mathrm{NMR}\left(125 \mathrm{MHz}, \mathrm{CDCl}_{3}\right) \delta 176.48,153.94,135.68,135.35,134.76$, $131.41,129.52,128.94,127.29,119.26,86.43,78.16,72.78,66.06,56.01,55.76,41.09,37.74$, 33.44, 26.16, 18.60, 17.16, 14.48, 13.60, -3.74, -4.86; MS (ESI) $546\left[\mathrm{M}+\mathrm{H}^{+}\right]$; HRMS (FAB) calcd. for $\mathrm{C}_{30} \mathrm{H}_{48} \mathrm{NO}_{6} \mathrm{Si}\left[\mathrm{M}+\mathrm{H}^{+}\right]$546.3251, found 546.3251.

Primary Alcohol 31: To a solution of aldol product $29(215 \mathrm{mg}, 0.394)$ in $\mathrm{CH}_{2} \mathrm{Cl}_{2}(5 \mathrm{~mL})$ at $\mathrm{rt}$ was added imidazole (107 mg, $1.58 \mathrm{mmol})$ and TESCl (198 $\mu \mathrm{L}, 1.18 \mathrm{mmol})$. After stirring for 12 $h$, the reaction mixture was treated with $\mathrm{H}_{2} \mathrm{O}$ and diluted with $\mathrm{CH}_{2} \mathrm{Cl}_{2}$. The organic layer was separated and the aqueous layer was extracted with $\mathrm{CH}_{2} \mathrm{Cl}_{2}(3 \mathrm{x})$. The combined organic layers were dried $\left(\mathrm{MgSO}_{4}\right)$ and concentrated under reduced pressure to afford the TES-protected aldol product 30. The crude product 30 was dissolved in THF $(5 \mathrm{~mL})$, and $\mathrm{MeOH}(64 \mu \mathrm{L}, 0.394$ mmol) and $\mathrm{LiBH}_{4}(35 \mathrm{mg}, 1.58 \mathrm{mmol})$ were added at $\mathrm{rt}$. After stirring for $1 \mathrm{~h}$, the reaction mixture was treated with $0.5 \mathrm{M} \mathrm{NaOH}$. The organic layer was separated and the aqueous layer was extracted with $\mathrm{Et}_{2} \mathrm{O}(3 \mathrm{x})$. The combined organic layers were dried $\left(\mathrm{MgSO}_{4}\right)$ and concentrated under reduced pressure. Purification of the crude product by FC (hexane/EtOAc 10:1) afforded primary alcohol $31\left(159 \mathrm{mg}, 83 \%\right.$ ) as a colorless oil. $[\alpha]_{\mathrm{D}}+10.9^{\circ}$ (c 2.38, $\mathrm{CHCl}_{3}$ ); IR (neat) 3460, 2970, 2930, 2880, 1460, 1380, 1250, 1130, 1060, 1020; ${ }^{1} \mathrm{H}-\mathrm{NMR}(500 \mathrm{MHz}$, $\left.\mathrm{CDCl}_{3}\right) \delta 5.60-5.53(\mathrm{~m}, 1 \mathrm{H}), 5.35-5.26(\mathrm{~m}, 3 \mathrm{H}), 4.31(\mathrm{~d}, J=9.1,1 \mathrm{H}), 3.68-3.58(\mathrm{~m}, 2 \mathrm{H}), 3.42-$ $3.34(\mathrm{~m}, 2 \mathrm{H}), 3.20(\mathrm{~s}, 3 \mathrm{H}), 3.13(\operatorname{app~d}, J=7.0,1 \mathrm{H}), 2.65-2.59(\mathrm{~m}, 1 \mathrm{H}), 1.94-1.88(\mathrm{~m}, 1 \mathrm{H}), 1.67$ $(\mathrm{d}, J=1.2,3 \mathrm{H}), 0.94$ (t, $J=8.0,9 \mathrm{H}), 0.93-0.91(\mathrm{~m}, 12 \mathrm{H}), 0.70(\mathrm{~d}, J=7.1,3 \mathrm{H}), 0.58(\mathrm{q}, J=8.0$, $6 \mathrm{H}), 0.04$ (s, 3H), 0.00 (s, 3H); ${ }^{13} \mathrm{C}-\mathrm{NMR}\left(125 \mathrm{MHz}, \mathrm{CDCl}_{3}\right) \delta 135.10,133.66,133.46,118.84$, 86.46, 78.30, 76.58, 68.33, 56.08, 38.87, 33.24, 26.13, 18.58, 17.70, 14.25, 12.64, 6.75, 4.74, $3.85,-4.89$; MS (ESI) $509\left[\mathrm{M}+\mathrm{Na}^{+}\right]$; HRMS (FAB) calcd. for $\mathrm{C}_{26} \mathrm{H}_{54} \mathrm{O}_{4} \mathrm{Si}_{2} \mathrm{Na}\left[\mathrm{M}+\mathrm{Na}^{+}\right]$ 509.3458, found 509.3468.

Glutarimide Aldehyde 5: Compound 5 was synthesized according to a literature procedure. ${ }^{5}$

Enone 33: To a solution of primary alcohol 31 (142 $\mathrm{mg}, 0.292 \mathrm{mmol})$ in $\mathrm{CH}_{2} \mathrm{Cl}_{2}(5 \mathrm{~mL})$ at $\mathrm{rt}$ was added Dess-Martin periodinane $(136 \mathrm{mg}, 0.321 \mathrm{mmol})$. After stirring for $45 \mathrm{~min}$, the reaction mixture was treated with saturated aqueous $\mathrm{Na}_{2} \mathrm{~S}_{2} \mathrm{O}_{3}$ solution and saturated aqueous $\mathrm{NaHCO}_{3}$ solution. The organic layer was separated and the aqueous layer was extracted with $\mathrm{CH}_{2} \mathrm{Cl}_{2}(3 \mathrm{x})$. The combined organic layers were dried $\left(\mathrm{MgSO}_{4}\right)$ and concentrated under reduced pressure. In a separate flask, dimethyl methylphosphonate $(316 \mu \mathrm{L}, 2.92 \mathrm{mmol})$ in THF $(2 \mathrm{~mL})$ at $-78{ }^{\circ} \mathrm{C}$ was treated with $\mathrm{BuLi}(1.64 \mathrm{~mL}, 2.62 \mathrm{mmol}, 1.6 \mathrm{M}$ in hexane). After stirring for 20

\footnotetext{
${ }^{5}$ Egawa, Y.; Suzuki, M.; Okuda, T. Chem. Pharm. Bull. 1963, 11, 589.
} 
min, the crude aldehyde obtained from the Dess-Martin oxidation was dissolved in THF ( $1 \mathrm{~mL})$ and added to the reaction mixture. The reaction mixture was warmed to $0{ }^{\circ} \mathrm{C}$, stirred for $15 \mathrm{~min}$, and then treated with saturated aqueous $\mathrm{NH}_{4} \mathrm{Cl}$ solution. The organic layer was separated and the aqueous layer was extracted with EtOAc (4x). The combined organic layers were dried $\left(\mathrm{MgSO}_{4}\right)$ and concentrated under reduced pressure. The crude product was dissolved in $\mathrm{CH}_{2} \mathrm{Cl}_{2}(5 \mathrm{~mL})$, and Dess-Martin periodinane (136 mg, $0.321 \mathrm{mmol}$ ) was added at rt. After stirring for $20 \mathrm{~min}$, the reaction mixture was treated with saturated aqueous $\mathrm{Na}_{2} \mathrm{~S}_{2} \mathrm{O}_{3}$ solution and saturated aqueous $\mathrm{NaHCO}_{3}$ solution. The organic layer was separated and the aqueous layer was extracted with $\mathrm{CH}_{2} \mathrm{Cl}_{2}$ (1x) and EtOAc (3x). The combined organic layers were dried $\left(\mathrm{MgSO}_{4}\right)$ and concentrated under reduced pressure. The crude phosphonate $\mathbf{3 2}$ was put under high vacuum for $1 \mathrm{hr}$. To a solution of the crude product $32 \mathrm{in} \mathrm{MeCN}(5 \mathrm{~mL})$ at rt was added anhydrous $\mathrm{LiCl}(25$ $\mathrm{mg}, 0.583 \mathrm{mmol})$ and $\mathrm{DBU}(87 \mu \mathrm{L}, 0.583 \mathrm{mmol})$. After stirring for $10 \mathrm{~min}$, a solution of glutarimide aldehyde $5(136 \mathrm{mg}, 0.875 \mathrm{mmol})$ in $\mathrm{MeCN}(1 \mathrm{~mL})$ was added. After stirring for $1 \mathrm{~h}$, the reaction mixture was treated with saturated aqueous $\mathrm{NH}_{4} \mathrm{Cl}$ solution and diluted with EtOAc. The organic layer was separated and the aqueous layer was extracted with EtOAc (3x). The combined organic layers were dried $\left(\mathrm{MgSO}_{4}\right)$ and concentrated under reduced pressure. Purification of the crude product by FC (hexane/EtOAc 4:1 $\rightarrow$ 2:1) afforded enone 33 (105 $\mathrm{mg}$, $57 \%$ ) as a colorless oil. $[\alpha]_{\mathrm{D}}+4.4^{\circ}\left(c 1.69, \mathrm{CHCl}_{3}\right)$; IR (neat) 2955, 2931, 2877, 2855, 1722, $1698,1628,1461,1377,1288,1254,1128,1066,1035 ;{ }^{1} \mathrm{H}-\mathrm{NMR}\left(500 \mathrm{MHz}, \mathrm{CDCl}_{3}\right) \delta 7.91$ (br s, $1 \mathrm{H}), 6.71-6.67(\mathrm{~m}, 1 \mathrm{H}), 6.26(\mathrm{~d}, J=15.9,1 \mathrm{H}), 5.65$ (ddd, $J=17.4,10.4,8.4,1 \mathrm{H}), 5.41-5.36(\mathrm{~m}$, 2H), $5.29(\mathrm{dd}, J=17.4,1.6,1 \mathrm{H}), 4.62(\mathrm{~d}, J=9.3,1 \mathrm{H}), 3.43(\operatorname{app~d}, J=7.2,1 \mathrm{H}), 3.38-3.33(\mathrm{~m}$, 1H), $3.21(\mathrm{~s}, 3 \mathrm{H}), 3.09-2.99(\mathrm{~m}, 1 \mathrm{H}), 2.75-2.66(\mathrm{~m}, 3 \mathrm{H}), 2.36-2.28(\mathrm{~m}, 5 \mathrm{H}), 1.66(\mathrm{~s}, 3 \mathrm{H}), 0.91(\mathrm{~s}$, 9H), 0.87-0.82 (m, 15H), 0.46 (q, $J=7.9,6 \mathrm{H}), 0.05$ (s, 3H), -0.01 (s, 3H); ${ }^{13} \mathrm{C}-\mathrm{NMR}(125 \mathrm{MHz}$, $\left.\mathrm{CDCl}_{3}\right) \delta 202.98,171.17,140.21,134.99,134.43,134.09,132.47,119.18,86.57,78.53,72.86$, $55.97,47.67,37.47,37.43,37.27,33.22,29.82,29.69,26.13,18.59,14.18,12.53,6.76,4.71$, $3.83,-4.91$; MS (ESI) $636\left[\mathrm{M}+\mathrm{H}^{+}\right]$; HRMS (FAB) calcd. for $\mathrm{C}_{34} \mathrm{H}_{62} \mathrm{NO}_{6} \mathrm{Si}_{2}\left[\mathrm{M}+\mathrm{H}^{+}\right] 636.4116$, found 636.4116 .

Secondary Alcohol 34: To a solution of enone $33(101 \mathrm{mg}, 0.159 \mathrm{mmol})$ in toluene $(4.5 \mathrm{~mL})$ at rt was added the Stryker reagent $(156 \mathrm{mg}, 0.079 \mathrm{mmol}$, dark red solid if quality is good). After stirring for $3.5 \mathrm{~h}$, hexane $(3 \mathrm{~mL})$ was added, and the reaction mixture was exposed to air, stirred for $20 \mathrm{~min}$, and concentrated under reduced pressure. Purification of the crude product by FC (hexane/EtOAc 6:1 $\rightarrow 2: 1$ ) afforded the corresponding saturated ketone as a colorless oil. $[\alpha]_{\mathrm{D}}$ $+7.7^{\circ}$ (c 3.00, $\mathrm{CHCl}_{3}$ ); IR (neat) 3217, 2954, 2932, 2877, 1713, 1459, 1377, 1253, 1126, 1061, 1035, 1006; ${ }^{1} \mathrm{H}-\mathrm{NMR}\left(500 \mathrm{MHz}, \mathrm{CDCl}_{3}\right) \delta 8.05$ (br s, $\left.1 \mathrm{H}\right), 5.63$ (ddd, $J=17.0,10.0,8.2,1 \mathrm{H}$ ), 
5.40-5.36 (m, 2H), $5.28(\mathrm{dd}, J=17.0,1.8,1 \mathrm{H}), 4.55(\mathrm{~d}, J=9.4,1 \mathrm{H}), 3.41(\mathrm{dd}, J=8.2,1.2,1 \mathrm{H})$, $3.35(\operatorname{app~t}, J=8.2,1 \mathrm{H}), 3.19(\mathrm{~s}, 3 \mathrm{H}), 2.82-2.64(\mathrm{~m}, 4 \mathrm{H}), 2.60-2.41(\mathrm{~m}, 2 \mathrm{H}), 2.29-2.23(\mathrm{~m}, 2 \mathrm{H})$, 2.18-2.10 (m, 1H), $1.62(\mathrm{~d}, J=1.2,3 \mathrm{H}), 1.61-1.53(\mathrm{~m}, 2 \mathrm{H}), 1.43-1.34(\mathrm{~m}, 2 \mathrm{H}), 0.92-0.90(\mathrm{~m}$, $12 \mathrm{H}), 0.86(\mathrm{t}, J=7.8,9 \mathrm{H}), 0.77(\mathrm{~d}, J=7.0,3 \mathrm{H}), 0.46(\mathrm{q}, J=7.8,6 \mathrm{H}), 0.03(\mathrm{~s}, 3 \mathrm{H}),-0.02(\mathrm{~s}, 3 \mathrm{H})$; ${ }^{13} \mathrm{C}-\mathrm{NMR}\left(125 \mathrm{MHz}, \mathrm{CDCl}_{3}\right) \delta 213.45,172.06,134.91,134.57,132.25,119.24,86.58,78.52$, 72.90, 55.94, 49.29, 44.53, 37.75, 34.32, 33.18, 30.44, 26.11, 19.97, 18.57, 17.16, 13.90, 12.46, 6.75, 4.71, -3.85, -4.93; MS (ESI) $638\left[\mathrm{M}+\mathrm{H}^{+}\right]$; HRMS (FAB) calcd. for $\mathrm{C}_{34} \mathrm{H}_{64} \mathrm{NO}_{6} \mathrm{Si}_{2}\left[\mathrm{M}+\mathrm{H}^{+}\right]$ 638.4272 , found 638.4273 .

A solution of the saturated ketone in HOAc $(3 \mathrm{~mL})$, THF $(1 \mathrm{~mL})$, and $\mathrm{H}_{2} \mathrm{O}(1 \mathrm{~mL})$ was stirred at rt for $2 \mathrm{~h}$. The reaction mixture was neutralized with solid $\mathrm{Na}_{2} \mathrm{CO}_{3}$ and diluted with $\mathrm{H}_{2} \mathrm{O}$ and EtOAc. The organic layer was separated and the aqueous layer was extracted with EtOAc (3x). The combined organic layers were dried $\left(\mathrm{MgSO}_{4}\right)$ and concentrated under reduced pressure. Purification of the crude product by FC (hexane/EtOAc 4:1 $\rightarrow$ 1:1) afforded secondary alcohol $34(68 \mathrm{mg}, 82 \%)$ as a white foam. $[\alpha]_{\mathrm{D}}+1.0^{\circ}\left(c \mathrm{1.00}, \mathrm{CHCl}_{3}\right)$; IR $\left(\mathrm{CHCl}_{3}\right) 3601,3366,3035$, 2931, 2861, 1708, 1455, 1378, 1249, 1120, 1026; ${ }^{1} \mathrm{H}-\mathrm{NMR}\left(500 \mathrm{MHz}, \mathrm{CDCl}_{3}\right) \delta 8.22$ (br s, $\left.1 \mathrm{H}\right)$, 5.63-5.56 (m, 1H), $5.48(\mathrm{~d}, J=9.3,1 \mathrm{H}), 5.33(\mathrm{dd}, J=10.3,1.5,1 \mathrm{H}), 5.27(\mathrm{dd}, J=17.2,1.5,1 \mathrm{H})$, $4.60(\mathrm{~d}, J=9.8,1 \mathrm{H}), 3.42-3.35(\mathrm{~m}, 2 \mathrm{H}), 3.18(\mathrm{~s}, 3 \mathrm{H}), 2.79-2.63(\mathrm{~m}, 4 \mathrm{H}), 2.58-2.54(\mathrm{~m}, 2 \mathrm{H})$, 2.29-2.23 (m, 2H), 2.18-2.10 (m, 1H), $1.95($ br s, $1 \mathrm{H}), 1.67(\mathrm{~d}, J=1.0,3 \mathrm{H}), 1.66-1.59(\mathrm{~m}, 2 \mathrm{H})$, $1.42-1.37(\mathrm{~m}, 2 \mathrm{H}), 0.91(\mathrm{~s}, 9 \mathrm{H}), 0.89(\mathrm{~d}, J=6.6,3 \mathrm{H}), 0.87(\mathrm{~d}, J=7.1,3 \mathrm{H}), 0.05(\mathrm{~s}, 3 \mathrm{H}), 0.01(\mathrm{~s}$, $3 \mathrm{H}) ;{ }^{13} \mathrm{C}-\mathrm{NMR}\left(125 \mathrm{MHz}, \mathrm{CDCl}_{3}\right) \delta 214.01,172.21,135.51,134.72,131.56,119.19,86.30$, 78.26, 71.69, 55.98, 48.87, 42.70, 37.73, 37.70, 34.08, 33.26, 30.32, 26.11, 20.07, 18.55, 17.35, 13.87, 13.63, -3.79, -4.90; MS (ESI) $546\left[\mathrm{M}+\mathrm{Na}^{+}\right]$; HRMS (FAB) calcd. for $\mathrm{C}_{28} \mathrm{H}_{49} \mathrm{NO}_{6} \mathrm{SiNa}$ $\left[\mathrm{M}+\mathrm{Na}^{+}\right]$546.3227, found 546.3227.

2,6-Heptadienoic Acid 6: Compound 6 can be prepared by $\gamma$-alkylation of crotonic acid with allyl bromide. ${ }^{6}$ However, it was found that the procedure described below is more convenient for larger scale preparations of 2,6-heptadienoic acid 6.

To a solution of oxalyl chloride $(3.36 \mathrm{~mL}, 39.2 \mathrm{mmol})$ in $\mathrm{CH}_{2} \mathrm{Cl}_{2}(100 \mathrm{~mL})$ at $-78{ }^{\circ} \mathrm{C}$ was added DMSO (5.56 mL, $78.3 \mathrm{mmol})$. After stirring for $5 \mathrm{~min}$, 4-penten-1-ol (2.00 mL, $19.6 \mathrm{mmol})$ was added, and after another $15 \mathrm{~min}^{\mathrm{Et}} \mathrm{t}_{3} \mathrm{~N}(13.6 \mathrm{~mL}, 97.9 \mathrm{mmol})$ was added. The reaction mixture was warmed to rt and then treated with $0.1 \mathrm{M} \mathrm{HCl}$. The organic layer was separated, washed with saturated aqueous $\mathrm{NaCl}$ solution, dried $\left(\mathrm{MgSO}_{4}\right)$, and treated with $\mathrm{Ph}_{3} \mathrm{PCHCO}_{2} t-\mathrm{Bu}(7.38 \mathrm{~g}, 19.6$ $\mathrm{mmol}$ ) at $\mathrm{rt}$. The reaction mixture was stirred for $5 \mathrm{~h}$ and then treated with saturated aqueous

\footnotetext{
${ }^{6}$ Katzenellenbogen, J. A.; Crumrine, A. L. J. Am. Chem. Soc. 1976, 98, 4925; Ahmar, M.; Duyck, C.; Fleming I. J. Chem. Soc., Perkin Trans. 1 1998, 2721.
} 
$\mathrm{NH}_{4} \mathrm{Cl}$ solution and diluted with $\mathrm{CH}_{2} \mathrm{Cl}_{2}$. The organic layer was separated and the aqueous layer was extracted with $\mathrm{CH}_{2} \mathrm{Cl}_{2}(3 \mathrm{x})$. The combined organic layers were dried $\left(\mathrm{MgSO}_{4}\right)$ and concentrated under reduced pressure. The crude product was filtered through a silica plug $\left(\mathrm{CH}_{2} \mathrm{Cl}_{2}\right.$ /pentane 1:1) to give $t$-butyl (E)-2,6-heptadienoate. To a solution of this ester in $\mathrm{CH}_{2} \mathrm{Cl}_{2}$ $(40 \mathrm{~mL})$ was added TFA $(5 \mathrm{~mL})$ at $\mathrm{rt}$. After stirring for $12 \mathrm{~h}$, the reaction mixture was concentrated under reduced pressure. Purification of the crude product by FC (hexane/EtOAc $15: 1 \rightarrow 5: 1)$ afforded 2,6-heptadienoic acid $6(1.67 \mathrm{~g}, 68 \%)$ as a colorless oil. ${ }^{1} \mathrm{H}-\mathrm{NMR}(400$ $\left.\mathrm{MHz} \mathrm{CDCl}_{3}\right) \delta 7.12-7.05(\mathrm{~m}, 1 \mathrm{H}), 5.88-5.76(\mathrm{~m}, 2 \mathrm{H}), 5.08-5.02(\mathrm{~m}, 2 \mathrm{H}), 2.37-2.32(\mathrm{~m}, 2 \mathrm{H})$, 2.26-2.21 (m, 2H).

Formation of the mixed anhydride: To a solution of 2,6-heptadienoic acid 6 (68 $\mathrm{mg}, 0.535$ $\mathrm{mmol})$ in toluene $(1 \mathrm{~mL})$ at $\mathrm{rt}$ was added 2,4,6-trichlorobenzoyl chloride ( $84 \mu \mathrm{L}, 0.535 \mathrm{mmol})$ and $i-\operatorname{Pr}_{2} \mathrm{NEt}(89 \mu \mathrm{L}, 0.508 \mathrm{mmol})$. The reaction mixture was stirred for $3 \mathrm{~h}$ and then used as it is as a stock solution $(0.54 \mathrm{M})$ for the subsequent acylation reactions.

Unsaturated Ester 35: To a solution of alcohol $34(41 \mathrm{mg}, 0.078 \mathrm{mmol})$ in toluene $(0.1 \mathrm{~mL})$ at rt was added pyridine $(25 \mu \mathrm{L}, 0.313 \mathrm{mmol})$ and the mixed anhydride ${ }^{7}$ (460 $\mu \mathrm{L}, 0.235 \mathrm{mmol}$, $0.54 \mathrm{M}$ in toluene). After stirring for $24 \mathrm{~h}$, the reaction mixture was directly loaded onto a silica column and purified by FC (hexane/EtOAc 10:1 $\rightarrow$ 4:1 $\rightarrow$ 2:1) to afford unsaturated ester 35 (33 $\mathrm{mg}, 67 \%)$ as a colorless oil. $\left.[\alpha]_{\mathrm{D}}-29.0^{\circ}(c) 1.00, \mathrm{CHCl}_{3}\right)$; IR (neat) 3214, 3081, 2930, 2856, 1722, 1452, 1377, 1256, 1126, 1028; ${ }^{1} \mathrm{H}-\mathrm{NMR}\left(500 \mathrm{MHz}, \mathrm{CDCl}_{3}\right) \delta 7.87$ (br s, 1H), 6.89 (app dt, $J=15.5,6.8,1 \mathrm{H}), 5.81-5.62(\mathrm{~m}, 4 \mathrm{H}), 5.61(\mathrm{dd}, J=10.3,1.2,1 \mathrm{H}), 5.38(\mathrm{dd}, J=10.3,1.8,1 \mathrm{H})$, $5.32(\mathrm{dd}, J=17.3,1.4,1 \mathrm{H}), 5.03-4.98(\mathrm{~m}, 2 \mathrm{H}), 3.43-3.39(\mathrm{~m}, 2 \mathrm{H}), 3.21(\mathrm{~s}, 3 \mathrm{H}), 3.00-2.85$ (m, $2 \mathrm{H}), 2.72-2.68(\mathrm{~m}, 2 \mathrm{H}), 2.56-2.44(\mathrm{~m}, 2 \mathrm{H}), 2.30-2.24(\mathrm{~m}, 4 \mathrm{H}), 2.23-2.08(\mathrm{~m}, 3 \mathrm{H}), 1.62(\mathrm{~s}, 3 \mathrm{H})$, 1.61-1.58 (m, 2H), 1.36-1.32 (m, 2H), $0.94(\operatorname{app~t,~} J=7.2,6 \mathrm{H}), 0.90$ (s, 9H), $0.06(\mathrm{~s}, 3 \mathrm{H}), 0.00$ (s, $3 \mathrm{H}) ;{ }^{13} \mathrm{C}-\mathrm{NMR}\left(125 \mathrm{MHz}, \mathrm{CDCl}_{3}\right) \delta 211.20,171.83,164.68,148.92,137.72,136.96,134.57$, $127.00,121.15,119.23,115.60,86.28,78.39$, 73.79, 56.03, 47.39, 41.45, 37.72, 34.16, 33.84, 31.97, 31.46, 30.40, 26.21, 26.13, 20.10, 18.59, 17.70, 13.72, 12.66, -3.76, -4.94; MS (ESI) 654 $\left[\mathrm{M}+\mathrm{Na}^{+}\right]$; HRMS (FAB) calcd. for $\mathrm{C}_{35} \mathrm{H}_{57} \mathrm{NO}_{7} \mathrm{SiNa}\left[\mathrm{M}+\mathrm{Na}^{+}\right] 654.3826$, found 654.3835 .

TBS-Migrastatin 37: To a solution of unsaturated ester $35(29 \mathrm{mg}, 0.046 \mathrm{mmol})$ in refluxing toluene $(100 \mathrm{~mL})$ was added Grubbs-II catalyst $16(8 \mathrm{mg}, 0.0092 \mathrm{mmol})$. After stirring for 15 min, the reaction mixture was cooled to $\mathrm{rt}$ and filtered through a silica plug (hexane/EtOAc 1:3). Purification of the crude product by FC (hexane/EtOAc $5: 1 \rightarrow 2: 1 \rightarrow 1: 1$ ) afforded TBS-

\footnotetext{
${ }^{7}$ See above for the preparation of a stock solution of the mixed anhydride in toluene.
} 
migrastatin $37(19 \mathrm{mg}, 69 \%)$ as a white solid. $[\alpha]_{\mathrm{D}}+13.7^{\circ}\left(c 0.50, \mathrm{CHCl}_{3}\right) ;{ }^{1} \mathrm{H}-\mathrm{NMR}(500 \mathrm{MHz}$, $\left.\mathrm{CDCl}_{3}\right) \delta 7.77(\mathrm{br} \mathrm{s}, 1 \mathrm{H}), 6.54-6.48(\mathrm{~m}, 1 \mathrm{H}), 5.59(\mathrm{~d}, J=15.7,1 \mathrm{H}), 5.56(\mathrm{~d}, J=10.7,1 \mathrm{H}), 5.51-$ $5.45(\mathrm{~m}, 1 \mathrm{H}), 5.22(\mathrm{dd}, J=15.4,4.6,1 \mathrm{H}), 5.08(\mathrm{~d}, J=9.5,1 \mathrm{H}), 3.39(\mathrm{dd}, J=8.1,4.6,1 \mathrm{H}), 3.19$ (s, 3H), 3.03 (app d, $J=7.8,1 \mathrm{H}), 2.98-2.92(\mathrm{~m}, 1 \mathrm{H}), 2.91-2.85(\mathrm{~m}, 1 \mathrm{H}), 2.73-2.68(\mathrm{~m}, 2 \mathrm{H}), 2.50$ (app t, $J=6.9,2 \mathrm{H}), 2.44-2.40(\mathrm{~m}, 2 \mathrm{H}), 2.29-2.09(\mathrm{~m}, 5 \mathrm{H}), 1.81(\mathrm{~d}, J=1.1,3 \mathrm{H}), 1.64-1.57$ (m, $2 \mathrm{H}), 1.37-1.31(\mathrm{~m}, 2 \mathrm{H}), 1.11(\mathrm{~d}, J=7.2,3 \mathrm{H}), 0.92-0.90(\mathrm{~m}, 12 \mathrm{H}), 0.04(\mathrm{~s}, 3 \mathrm{H}),-0.01(\mathrm{~s}, 3 \mathrm{H})$; ${ }^{13} \mathrm{C}-\mathrm{NMR}\left(125 \mathrm{MHz}, \mathrm{CDCl}_{3}\right) \delta 210.81,171.82,163.80,150.36,133.94,130.17,129.49,128.78$, $121.88,83.37,79.25,76.82$, 56.68, 51.15, 40.24, 37.70, 37.68, 34.17, 33.47, 31.15, 30.36, 30.27, 26.29, 20.12, 18.63, 13.61, 13.30, -3.61, -4.95; MS (ESI) $626\left[\mathrm{M}+\mathrm{Na}^{+}\right]$; HRMS (FAB) calcd. for $\mathrm{C}_{33} \mathrm{H}_{53} \mathrm{NO}_{7} \mathrm{SiNa}\left[\mathrm{M}+\mathrm{Na}^{+}\right]$626.3489, found 626.3489.

Migrastatin 1: To a solution of TBS-migrastatin $37(19 \mathrm{mg}, 0.032 \mathrm{mmol})$ in THF $(1.5 \mathrm{~mL})$ at $\mathrm{rt}$ was added $\mathrm{HF} \bullet$ pyridine $(0.25 \mathrm{~mL})$. After stirring for $15 \mathrm{~h}$, the reaction mixture was carefully treated with MeOTMS (3 mL) and concentrated under reduced pressure. Purification of the crude product by FC (hexane/EtOAc $2: 1 \rightarrow 1: 1 \rightarrow 1: 2)$ afforded migrastatin $1(13 \mathrm{mg}, 85 \%)$ as a white solid. $[\alpha]_{\mathrm{D}}+12.6^{\circ}$ (c $\left.0.50, \mathrm{MeOH}\right) ;{ }^{1} \mathrm{H}-\mathrm{NMR}\left(500 \mathrm{MHz}, \mathrm{CDCl}_{3}\right) \delta 7.82$ (br s, $\left.1 \mathrm{H}\right), 6.49$ $(\mathrm{ddd}, J=15.7,10.5,3.7,1 \mathrm{H}), 5.64(\mathrm{dd}, J=10.7,1.2,1 \mathrm{H}), 5.58(\mathrm{dd}, J=15.7,1.2,1 \mathrm{H}), 5.54-5.48$ (m, 1H), $5.24(\mathrm{dd}, J=15.5,4.7,1 \mathrm{H}), 5.08(\mathrm{~d}, J=10.0,1 \mathrm{H}), 3.47(\mathrm{dd}, J=8.7,4.7,1 \mathrm{H}), 3.30$ (s, $3 \mathrm{H}), 3.03$ (dd, $J=8.7,1.7,1 \mathrm{H}), 2.99-2.87$ (m, 2H), 2.80 (br s, 1H), 2.73-2.68 (m, 2H), 2.50 (app $\mathrm{t}, J=6.9,2 \mathrm{H}), 2.44-2.39(\mathrm{~m}, 2 \mathrm{H}), 2.28-2.17(\mathrm{~m}, 4 \mathrm{H}), 2.16-2.08(\mathrm{~m}, 1 \mathrm{H}), 1.86(\mathrm{~d}, J=1.2,3 \mathrm{H})$, 1.69-1.55 (m, 2H), 1.41-1.30 (m, 2H), $1.12(\mathrm{~d}, J=7.2,3 \mathrm{H}), 0.96(\mathrm{~d}, J=6.9,3 \mathrm{H}) ;{ }^{13} \mathrm{C}-\mathrm{NMR}(125$ $\left.\mathrm{MHz}, \mathrm{CDCl}_{3}\right) \delta 210.88,171.78,163.86,150.01,132.99,131.17,130.46,127.87,122.08,82.39$, 77.92, 76.92, 56.93, 51.18, 39.88, 37.68, 37.66, 34.12, 31.93, 31.08, 30.34, 30.09, 25.99, 20.09, 13.39; MS (ESI) $512\left[\mathrm{M}+\mathrm{Na}^{+}\right]$; HRMS (FAB) calcd. for $\mathrm{C}_{27} \mathrm{H}_{39} \mathrm{NO}_{7} \mathrm{Na}\left[\mathrm{M}+\mathrm{Na}^{+}\right] 512.2624$, found 512.2604 .

6-Heptenoyl Chloride 38: To a solution of 6-heptenoic acid $(251 \mu \mathrm{L}, 1.85 \mathrm{mmol})$ in $\mathrm{CH}_{2} \mathrm{Cl}_{2}(5$ $\mathrm{mL})$ at $\mathrm{rt}$ was added oxalyl chloride $(476 \mu \mathrm{L}, 5.55 \mathrm{mmol})$ and DMF (1 drop). After stirring for 1 $\mathrm{hr}$, the reaction mixture was concentrated under reduced pressure and put under high vacuum for 15 min. The residual yellow oil was dissolved in $\mathrm{CH}_{2} \mathrm{Cl}_{2}(3 \mathrm{~mL})$ and used as a stock solution $(0.62 \mathrm{M})$ for the subsequent acylation reactions.

Ester 39: To a solution of alcohol $34(37 \mathrm{mg}, 0.070 \mathrm{mmol})$ in $\mathrm{CH}_{2} \mathrm{Cl}_{2}(2 \mathrm{~mL})$ at $\mathrm{rt}$ was added DMAP (17 mg, $0.139 \mathrm{mmol})$ and 6-heptenoyl chloride ${ }^{8} 38(202 \mu \mathrm{L}, 0.125 \mathrm{mmol}, 0.62 \mathrm{M}$ in $\mathrm{CH}_{2} \mathrm{Cl}_{2}$ ). After stirring for $2 \mathrm{~h}$, the reaction mixture was treated with $0.1 \mathrm{M} \mathrm{HCl}$ and diluted with

\footnotetext{
${ }^{8}$ See above for the preparation of a stock solution of 6-heptenoyl chloride 38 in $\mathrm{CH}_{2} \mathrm{Cl}_{2}$.
} 
$\mathrm{CH}_{2} \mathrm{Cl}_{2}$. The organic layer was separated and the aqueous layer was extracted with $\mathrm{CH}_{2} \mathrm{Cl}_{2}(3 \mathrm{x})$. The combined organic layers were dried $\left(\mathrm{MgSO}_{4}\right)$ and concentrated under reduced pressure. Purification of the crude product by FC (hexane/EtOAc 10:1 $\rightarrow$ 4:1 $\rightarrow$ 2:1) afforded ester 39 (31 $\mathrm{mg}, 69 \%)$ as a colorless oil. ${ }^{1} \mathrm{H}-\mathrm{NMR}\left(500 \mathrm{MHz}, \mathrm{CDCl}_{3}\right) \delta 8.22(\mathrm{br} \mathrm{s}, 1 \mathrm{H}), 5.79-5.72(\mathrm{~m}, 1 \mathrm{H})$, $5.67-5.61(\mathrm{~m}, 2 \mathrm{H}), 5.55(\mathrm{~d}, J=10.3,1 \mathrm{H}), 5.36(\mathrm{dd}, J=10.3,1.3,1 \mathrm{H}), 5.30(\mathrm{~d}, J=17.1,1 \mathrm{H})$, 5.00-4.92 (m, 2H), 3.40-3.37 (m, 2H), $3.20(\mathrm{~s}, 3 \mathrm{H}), 2.93-2.85(\mathrm{~m}, 2 \mathrm{H}), 2.71(\mathrm{dd}, J=17.0,4.0$, $2 \mathrm{H}), 2.55-2.42(\mathrm{~m}, 2 \mathrm{H}), 2.29-2.21(\mathrm{~m}, 2 \mathrm{H}), 2.19-2.11(\mathrm{~m}, 3 \mathrm{H}), 2.09-2.00(\mathrm{~m}, 2 \mathrm{H}), 1.60(\mathrm{~s}, 3 \mathrm{H})$, 1.59-1.51 (m, 5H), 1.47-1.42 (m, 1H), 1.38-1.32 (m, 2H), 0.92-0.90 (m, 15H), 0.05 (s, 3H), -0.01 (s, $3 \mathrm{H}) ;{ }^{13} \mathrm{C}-\mathrm{NMR}\left(125 \mathrm{MHz}, \mathrm{CDCl}_{3}\right) \delta 211.06,172.07,171.68,138.28,137.75,134.48,126.86$, $119.24,114.73,86.25,78.39,73.62,56.01,47.13,41.67,37.70,34.18,34.08,33.78,33.28$, 30.41, 28.21, 28.18, 26.11, 24.38, 20.12, 18.56, 17.61, 13.73, 12.64, -3.78, -4.97; MS (ESI) 656 $\left[\mathrm{M}+\mathrm{Na}^{+}\right]$; HRMS (FAB) calcd. for $\mathrm{C}_{35} \mathrm{H}_{59} \mathrm{NO}_{7} \mathrm{SiNa}\left[\mathrm{M}+\mathrm{Na}^{+}\right] 656.3959$, found 656.3956 .

TBS-2,3-Dihydromigrastatin 40: To a solution of ester $39(31 \mathrm{mg}, 0.048 \mathrm{mmol})$ in refluxing toluene $(100 \mathrm{~mL})$ was added Grubbs-II catalyst $16(8 \mathrm{mg}, 0.0094 \mathrm{mmol})$. After stirring for 15 min, the reaction mixture was cooled to $\mathrm{rt}$ and filtered through a silica plug (hexane/EtOAc 1:3). Purification of the crude product by FC (hexane/EtOAc $5: 1 \rightarrow 2: 1 \rightarrow 1: 1$ ) afforded TBS-2,3dihydromigrastatin 40 (23 mg, 79\%) as a colorless oil. ${ }^{1} \mathrm{H}-\mathrm{NMR}\left(500 \mathrm{MHz}, \mathrm{CDCl}_{3}\right) \delta 7.90$ (br s, $1 \mathrm{H}), 5.65-5.57(\mathrm{~m}, 2 \mathrm{H}), 5.35$ (dd, $J=15.7,5.1,1 \mathrm{H}), 5.20(\mathrm{~d}, J=9.2,1 \mathrm{H}), 3.43-3.40(\mathrm{~m}, 1 \mathrm{H})$, 3.23-3.20 (m, 1H), $3.21(\mathrm{~s}, 3 \mathrm{H}), 3.03-2.98(\mathrm{~m}, 1 \mathrm{H}), 2.95-2.91(\mathrm{~m}, 1 \mathrm{H}), 2.73-2.69(\mathrm{~m}, 2 \mathrm{H}), 2.59-$ $2.43(\mathrm{~m}, 2 \mathrm{H}), 2.33-2.22(\mathrm{~m}, 4 \mathrm{H}), 2.17-2.07(\mathrm{~m}, 3 \mathrm{H}), 1.75(\mathrm{~d}, J=0.9,3 \mathrm{H}), 1.61-1.55(\mathrm{~m}, 5 \mathrm{H})$, $1.40-1.35$ (m, 3H), 1.07 (d, $J=7.2,3 \mathrm{H}), 0.94$ (d, $J=6.8,3 \mathrm{H}), 0.91$ (s, 9H), 0.07 (s, 3H), 0.03 (s, $3 \mathrm{H}) ;{ }^{13} \mathrm{C}-\mathrm{NMR}\left(125 \mathrm{MHz}, \mathrm{CDCl}_{3}\right) \delta 210.63,171.84,171.80,134.70,131.22,129.51,128.39$, $82.98,79.10,76.46,56.49,51.24,40.62,37.74,37.69,34.18,33.35,33.18,31.11,30.37,26.29$,

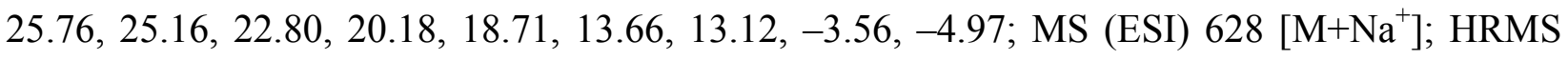
(FAB) calcd. for $\mathrm{C}_{33} \mathrm{H}_{55} \mathrm{NO}_{7} \mathrm{Na}\left[\mathrm{M}+\mathrm{Na}^{+}\right] 628.3646$, found 628.3644 .

2,3-Dihydromigrastatin 41: To a solution of TBS-2,3-dihydromigrastatin 40 (23 mg, 0.038 mmol) in THF $(1.5 \mathrm{~mL})$ at $\mathrm{rt}$ was added HF•pyridine $(0.3 \mathrm{~mL})$. After stirring for $15 \mathrm{~h}$, the reaction mixture was carefully treated with MeOTMS $(4 \mathrm{~mL})$ and concentrated under reduced pressure. Purification of the crude product by FC (hexane/EtOAc 2:1 $\rightarrow$ 1:1 $\rightarrow$ 1:2) afforded 2,3-dihydromigrastatin $41(15 \mathrm{mg}, 81 \%)$ as a white foam. ${ }^{1} \mathrm{H}-\mathrm{NMR}\left(500 \mathrm{MHz}, \mathrm{CDCl}_{3}\right) \delta 7.97$ (br s, $1 \mathrm{H}), 5.68-5.60(\mathrm{~m}, 2 \mathrm{H}), 5.34(\mathrm{dd}, J=15.6,5.6,1 \mathrm{H}), 5.19(\mathrm{~d}, J=9.7,1 \mathrm{H}), 3.49-3.46(\mathrm{~m}$, $1 \mathrm{H}), 3.33$ (s, 3H), 3.22 (app d, $J=9.1,1 \mathrm{H}), 3.07-3.00(\mathrm{~m}, 1 \mathrm{H}), 2.98-2.91(\mathrm{~m}, 1 \mathrm{H}), 2.72$ (dd, $J=$ $17.1,2.3,2 \mathrm{H}), 2.59-2.50(\mathrm{~m}, 1 \mathrm{H}), 2.49-2.40(\mathrm{~m}, 1 \mathrm{H}), 2.30-2.04(\mathrm{~m}, 7 \mathrm{H}), 1.79(\mathrm{~d}, J=1.3,3 \mathrm{H})$, $1.63-1.56$ (m, 4H), 1.55-1.48 (m, 1H), 1.42-1.35 (m, 3H), 1.09 (d, $J=7.2,3 \mathrm{H}), 0.99$ (d, $J=6.9$, 
$3 \mathrm{H}) ;{ }^{13} \mathrm{C}-\mathrm{NMR}\left(125 \mathrm{MHz}, \mathrm{CDCl}_{3}\right) \delta 210.64,171.88,171.73,133.95,132.35,130.27,128.05$, $81.92,77.42,76.45,56.70,51.38,40.37,37.73,37.68,34.15,32.50,31.72,30.45,30.35,25.94$,

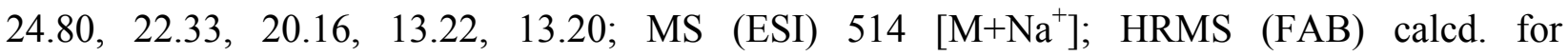
$\mathrm{C}_{27} \mathrm{H}_{41} \mathrm{NO}_{7} \mathrm{Na}\left[\mathrm{M}+\mathrm{Na}^{+}\right]$514.2781, found 514.2768.

$N$-Methyl-2,3-Dihydromigrastatin 42: To a solution of 2,3-dihydromigrastatin 41 (4 mg, $0.0081 \mathrm{mmol}$ ) in acetone $\left(0.4 \mathrm{~mL}\right.$ ) at $\mathrm{rt}$ was added MeI (excess) and $\mathrm{Cs}_{2} \mathrm{CO}_{3}$ (excess). After stirring for $4 \mathrm{~h}$, the reaction mixture was concentrated under reduced pressure to a volume of ca. $0.2 \mathrm{~mL}$. Purification of the residual solution by preparative TLC (hexane/EtOAc 1:2) afforded $\mathrm{N}$ methyl-2,3-dihydromigrastatin $42(3.5 \mathrm{mg}, 85 \%)$ as a colorless oil. ${ }^{1} \mathrm{H}-\mathrm{NMR}\left(500 \mathrm{MHz}, \mathrm{CDCl}_{3}\right)$ $\delta 5.68-5.61(\mathrm{~m}, 2 \mathrm{H}), 5.34(\mathrm{dd}, J=15.6,5.6,1 \mathrm{H}), 5.19(\mathrm{~d}, J=9.6,1 \mathrm{H}), 3.49-3.46(\mathrm{~m}, 1 \mathrm{H}), 3.33$ (s, 3H), 3.22 (app d, $J=9.1,1 \mathrm{H}), 3.14(\mathrm{~s}, 3 \mathrm{H}), 3.07-3.01(\mathrm{~m}, 1 \mathrm{H}), 2.95-2.89(\mathrm{~m}, 1 \mathrm{H}), 2.82-2.78$ (m, $2 \mathrm{H}), 2.58-2.50(\mathrm{~m}, 1 \mathrm{H}), 2.49-2.42(\mathrm{~m}, 1 \mathrm{H}), 2.33-2.27(\mathrm{~m}, 2 \mathrm{H}), 2.25-2.04(\mathrm{~m}, 5 \mathrm{H}), 1.79(\mathrm{~d}, J$ $=1.3,3 \mathrm{H}), 1.65-1.52(\mathrm{~m}, 5 \mathrm{H}), 1.47-1.42(\mathrm{~m}, 1 \mathrm{H}), 1.37-1.31(\mathrm{~m}, 2 \mathrm{H}), 1.09(\mathrm{~d}, J=7.2,3 \mathrm{H}), 0.99$ $(\mathrm{d}, J=6.9,3 \mathrm{H}) ;{ }^{13} \mathrm{C}-\mathrm{NMR}\left(125 \mathrm{MHz}, \mathrm{CDCl}_{3}\right) \delta 210.67,172.20,171.72,133.93,132.35,130.33$, $128.06,81.92,77.45,76.47,56.72,51.38,40.44,38.75,38.71,34.27,32.51,31.73,30.47,29.34$,

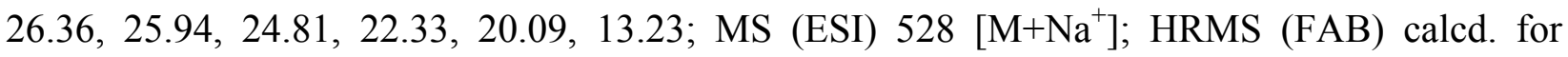
$\mathrm{C}_{28} \mathrm{H}_{43} \mathrm{NO}_{7} \mathrm{Na}\left[\mathrm{M}+\mathrm{Na}^{+}\right]$528.2937, found 528.2939.

Unsaturated Ester 43: To a solution of alcohol $26(109 \mathrm{mg}, 0.346 \mathrm{mmol})$ in toluene $(1 \mathrm{~mL})$ at rt was added pyridine $(84 \mu \mathrm{L}, 1.04 \mathrm{mmol})$ and the mixed anhydride $9(1 \mathrm{~mL}, 0.535 \mathrm{mmol}, 0.54 \mathrm{M}$ in toluene). After stirring for $12 \mathrm{~h}$, the reaction mixture was filtered through a silica plug (hexane/EtOAc 30:1). Purification of the crude product by FC (pentane $/ \mathrm{CH}_{2} \mathrm{Cl}_{2} 3: 1 \rightarrow 2: 1$ ) afforded unsaturated ester $\mathbf{4 3}(70 \mathrm{mg}, 48 \%)$ as a colorless oil. $[\alpha]_{\mathrm{D}}+2.6^{\circ}\left(c 1.00, \mathrm{CHCl}_{3}\right)$; IR $\left(\mathrm{CHCl}_{3}\right)$ 2934, 2882, 2851, 1705, 1653, 1470, 1381, 1246, 1126, 1079, 1026; ${ }^{1} \mathrm{H}-\mathrm{NMR}(500$ $\left.\mathrm{MHz}, \mathrm{CDCl}_{3}\right) \delta 6.99-6.93(\mathrm{~m}, 1 \mathrm{H}), 5.86-5.76(\mathrm{~m}, 2 \mathrm{H}), 5.66-5.59(\mathrm{~m}, 1 \mathrm{H}), 5.44(\mathrm{~d}, J=9.5,1 \mathrm{H})$, 5.29-5.22 (m, 2H), 5.07-4.99 (m, 2H), 4.61 (d, $J=12.1,1 \mathrm{H}), 4.57$ (d, $J=12.1,1 \mathrm{H}), 3.47$ (dd, $J=$ $7.2,2.9,1 \mathrm{H}), 3.37$ (app t, $J=7.7,1 \mathrm{H}), 3.19(\mathrm{~s}, 3 \mathrm{H}), 2.63-2.59(\mathrm{~m}, 1 \mathrm{H}), 2.33-2.28(\mathrm{~m}, 2 \mathrm{H}), 2.24-$ 2.19 (m, 2H), 1.73 (d, $J=1.3,3 \mathrm{H}), 0.91(\mathrm{~d}, J=6.6,3 \mathrm{H}), 0.90$ (s, 9H), $0.05(\mathrm{~s}, 3 \mathrm{H}), 0.02$ (s, 3H); ${ }^{13} \mathrm{C}-\mathrm{NMR}\left(125 \mathrm{MHz}, \mathrm{CDCl}_{3}\right) \delta 166.57,148.47,137.05,135.58,135.10,128.21,121.52,118.79$, 115.53, 86.26, 78.37, 63.07, 56.06, 34.26, 32.02, 31.48, 26.15, 21.49, 18.54, 13.96, -3.80, -4.85; MS (ESI) $445\left[\mathrm{M}+\mathrm{Na}^{+}\right]$; HRMS (FAB) calcd. for $\mathrm{C}_{24} \mathrm{H}_{43} \mathrm{O}_{4} \mathrm{Si}\left[\mathrm{M}+\mathrm{H}^{+}\right]$423.2931, found 423.2929.

TBS-Migrastatin Core 44: To a solution of unsaturated ester $43(35 \mathrm{mg}, 0.083 \mathrm{mmol})$ in refluxing toluene $(125 \mathrm{~mL})$ was added Grubbs-II catalyst $16(14 \mathrm{mg}, 0.017 \mathrm{mmol})$. After stirring

\footnotetext{
${ }^{9}$ See above for the preparation of a stock solution of the mixed anhydride in toluene.
} 
for $15 \mathrm{~min}$, the reaction mixture was cooled to rt and filtered through a silica plug (hexane/EtOAc 4:1). Purification of the crude product by FC (hexane/EtOAc 20:1) afforded TBS-migrastatin core $44(18 \mathrm{mg}, 55 \%)$ as a colorless oil. ${ }^{1} \mathrm{H}-\mathrm{NMR}\left(500 \mathrm{MHz}, \mathrm{CDCl}_{3}\right) \delta 6.85-6.79(\mathrm{~m}, 1 \mathrm{H}), 5.74$ $(\mathrm{d}, J=15.9,1 \mathrm{H}), 5.56-5.50(\mathrm{~m}, 2 \mathrm{H}), 5.12(\mathrm{dd}, J=15.5,8.7,1 \mathrm{H}), 4.68(\mathrm{~d}, J=15.8,1 \mathrm{H}), 4.62(\mathrm{~d}$, $J=15.8,1 \mathrm{H}), 3.44(\mathrm{dd}, J=8.3,1.4,1 \mathrm{H}), 3.33-3.30(\mathrm{~m}, 1 \mathrm{H}), 3.17(\mathrm{~s}, 3 \mathrm{H}), 3.03-2.97(\mathrm{~m}, 1 \mathrm{H})$, 2.47-2.36 (m, 2H), 2.31-2.24 (m, 1H), 2.21-2.14 (m, 1H), $1.64(\mathrm{~s}, 3 \mathrm{H}), 0.92(\mathrm{~s}, 9 \mathrm{H}), 0.83(\mathrm{~d}, J=$ 6.8, 3H), 0.07 (s, 3H), $0.06(\mathrm{~s}, 3 \mathrm{H}) ;{ }^{13} \mathrm{C}-\mathrm{NMR}\left(125 \mathrm{MHz}, \mathrm{CDCl}_{3}\right) \delta 165.37,149.91,131.98$, $130.48,126.58,121.83,117.57,85.82,77.49,65.56,55.83,33.11,32.46,30.01,26.27,22.17$, 18.71, 12.90, -3.57, -5.02; MS (ESI) $417\left[\mathrm{M}+\mathrm{Na}^{+}\right]$; HRMS (FAB) calcd. for $\mathrm{C}_{22} \mathrm{H}_{38} \mathrm{O}_{4} \mathrm{SiNa}$ $\left[\mathrm{M}+\mathrm{Na}^{+}\right]$417.2437, found 417.2456.

Migrastatin Core 45: To a solution of TBS-migrastatin core $44(18 \mathrm{mg}, 0.0457 \mathrm{mmol})$ in THF $(1.5 \mathrm{~mL})$ at $\mathrm{rt}$ was added $\mathrm{HF} \bullet$ pyridine $(0.3 \mathrm{~mL})$. After stirring for $14 \mathrm{~h}$, the reaction mixture was carefully treated with MeOTMS $(4 \mathrm{~mL})$ and concentrated under reduced pressure. Purification of the crude product by FC (hexane/EtOAc 10:1 $\rightarrow 5: 1$ ) afforded migrastatin core $45(8.5 \mathrm{mg}, 66 \%)$ as a colorless oil. $[\alpha]_{\mathrm{D}}+106.0^{\circ}\left(c 0.50, \mathrm{CHCl}_{3}\right)$; IR $\left(\mathrm{CHCl}_{3}\right) 3567,2933,2881,1716,1602$, $1448,1393,1255,1107,1052 ;{ }^{1} \mathrm{H}-\mathrm{NMR}\left(500 \mathrm{MHz}, \mathrm{CDCl}_{3}\right) \delta 6.81-6.75(\mathrm{~m}, 1 \mathrm{H}), 5.73(\mathrm{~d}, J=$ $15.9,1 \mathrm{H}), 5.62-5.55(\mathrm{~m}, 2 \mathrm{H}), 5.14(\mathrm{dd}, J=15.2,6.8,1 \mathrm{H}), 4.72(\mathrm{~d}, J=15.6,1 \mathrm{H}), 4.63$ (d, $J=$ 15.6, 1H), 3.42-3.38 (m, 2H), $3.28(\mathrm{~s}, 3 \mathrm{H}), 3.03-2.97(\mathrm{~m}, 1 \mathrm{H}), 2.69$ (br s, $1 \mathrm{H}), 2.47-2.38(\mathrm{~m}, 2 \mathrm{H})$, 2.32-2.18 (m, 2H), $1.68(\mathrm{~s}, 3 \mathrm{H}), 0.88(\mathrm{~d}, J=6.9,3 \mathrm{H}) ;{ }^{13} \mathrm{C}-\mathrm{NMR}\left(125 \mathrm{MHz}, \mathrm{CDCl}_{3}\right) \delta 165.36$, 149.52, 133.85, 129.79, 129.51, 127.50, 122.15, 84.62, 76.09, 65.40, 56.25, 32.20, 31.34, 29.99, 22.27, 12.66; MS (ESI) $303\left[\mathrm{M}+\mathrm{Na}^{+}\right]$; HRMS (FAB) calcd. for $\mathrm{C}_{16} \mathrm{H}_{24} \mathrm{O}_{4} \mathrm{Na}\left[\mathrm{M}+\mathrm{Na}^{+}\right]$303.1571, found 303.1572 .

Ester 46: To a solution of alcohol $26(275 \mathrm{mg}, 0.874 \mathrm{mmol})$ in $\mathrm{CH}_{2} \mathrm{Cl}_{2}(3 \mathrm{~mL})$ at $\mathrm{rt}$ was added DMAP (214 mg, $1.75 \mathrm{mmol})$ and 6-heptenoyl chloride ${ }^{10} 38(2.5 \mathrm{~mL}, 1.57 \mathrm{mmol}, 0.62 \mathrm{M}$ in $\mathrm{CH}_{2} \mathrm{Cl}_{2}$ ). After stirring for $20 \mathrm{~min}$, the reaction mixture was treated with $0.1 \mathrm{M} \mathrm{HCl}$ and diluted with $\mathrm{CH}_{2} \mathrm{Cl}_{2}$. The organic layer was separated and the aqueous layer was extracted with $\mathrm{CH}_{2} \mathrm{Cl}_{2}$ $(3 \mathrm{x})$. The combined organic layers were dried $\left(\mathrm{MgSO}_{4}\right)$ and concentrated under reduced pressure. Purification of the crude product by FC (hexane/EtOAc 30:1) afforded ester 46 (302 $\mathrm{mg}, 82 \%)$ as a colorless oil. $[\alpha]_{\mathrm{D}}+3.0^{\circ}\left(c 0.50, \mathrm{CHCl}_{3}\right)$; IR $\left(\mathrm{CHCl}_{3}\right) 2980,2933,2863,1722$, $1458,1382,1252,1112,1024 ;{ }^{1} \mathrm{H}-\mathrm{NMR}\left(500 \mathrm{MHz}, \mathrm{CDCl}_{3}\right) \delta 5.83-5.75(\mathrm{~m}, 1 \mathrm{H}), 5.66-5.59(\mathrm{~m}$, $1 \mathrm{H}), 5.43(\mathrm{~d}, J=9.5,1 \mathrm{H}), 5.30-5.23(\mathrm{~m}, 2 \mathrm{H}), 5.03-4.94(\mathrm{~m}, 2 \mathrm{H}), 4.56(\mathrm{~d}, J=12.0,1 \mathrm{H}), 4.51(\mathrm{~d}, J$ $=12.0,1 \mathrm{H}), 3.46(\mathrm{dd}, J=7.2,2.9,1 \mathrm{H}), 3.37($ app t, $J=7.7,1 \mathrm{H}), 3.20(\mathrm{~s}, 3 \mathrm{H}), 2.61-2.57(\mathrm{~m}, 1 \mathrm{H})$, $2.32(\operatorname{app~t}, J=7.5,2 \mathrm{H}), 2.06(\operatorname{app~q}, J=7.2,2 \mathrm{H}), 1.74(\mathrm{~d}, J=1.2,3 \mathrm{H}), 1.68-1.62(\mathrm{~m}, 2 \mathrm{H}), 1.45-$

\footnotetext{
${ }^{10}$ See above for the preparation of a stock solution of 6-heptenoyl chloride 38 in $\mathrm{CH}_{2} \mathrm{Cl}_{2}$.
} 
$1.39(\mathrm{~m}, 2 \mathrm{H}), 0.91(\mathrm{~s}, 9 \mathrm{H}), 0.90(\mathrm{~d}, J=6.5,3 \mathrm{H}), 0.05(\mathrm{~s}, 3 \mathrm{H}), 0.02(\mathrm{~s}, 3 \mathrm{H}) ;{ }^{13} \mathrm{C}-\mathrm{NMR}(125 \mathrm{MHz}$, $\left.\mathrm{CDCl}_{3}\right) \delta 173.65,138.40,135.59,135.10,128.12,118.77,114.67,86.24,78.36,63.11,56.07$, $34.24,34.17,33.35,28.35,26.15,24.46,21.45,18.54,13.98,-3.80,-4.85$; MS (ESI) 447 $\left[\mathrm{M}+\mathrm{Na}^{+}\right]$; HRMS (FAB) calcd. for $\mathrm{C}_{24} \mathrm{H}_{44} \mathrm{O}_{4} \mathrm{SiNa}\left[\mathrm{M}+\mathrm{Na}^{+}\right]$447.2906, found 447.2893.

TBS-Macrolactone 47: To a solution of ester 46 (95 mg, $0.224 \mathrm{mmol})$ in refluxing toluene (450 $\mathrm{mL}$ ) was added Grubbs-II catalyst $16(38 \mathrm{mg}, 0.045 \mathrm{mmol})$. After stirring for $15 \mathrm{~min}$, the reaction mixture was cooled to $\mathrm{rt}$ and filtered through a silica plug (hexane/EtOAc 5:1). Purification of the crude product by FC (hexane/EtOAc 30:1) afforded TBS-macrolactone 47 (67 $\mathrm{mg}, 76 \%)$ as a colorless oil. ${ }^{1} \mathrm{H}-\mathrm{NMR}\left(500 \mathrm{MHz}^{\mathrm{CDCl}}{ }_{3}\right) \delta 5.71-5.65(\mathrm{~m}, 1 \mathrm{H}), 5.56(\mathrm{~d}, J=10.0$, $1 \mathrm{H}), 5.28(\mathrm{dd}, J=15.7,8.0,1 \mathrm{H}), 4.52$ (d, $J=13.9,1 \mathrm{H}), 4.35$ (d, $J=13.9,1 \mathrm{H}), 3.46$ (dd, $J=7.7$, 2.6, $1 \mathrm{H}), 3.39(\operatorname{app~t}, J=7.8,1 \mathrm{H}), 3.20(\mathrm{~s}, 3 \mathrm{H}), 2.85-2.82(\mathrm{~m}, 1 \mathrm{H}), 2.42-2.36(\mathrm{~m}, 1 \mathrm{H}), 2.26-2.20$ (m, 1H), 2.18-2.14 (m, 1H), 2.11-2.06 (m, 1H), 1.77-1.72 (m, 1H), $1.71(\mathrm{~d}, J=1.1,3 \mathrm{H}), 1.62-$ $1.50(\mathrm{~m}, 2 \mathrm{H}), 1.46-1.40(\mathrm{~m}, 1 \mathrm{H}), 0.91(\mathrm{~s}, 9 \mathrm{H}), 0.88(\mathrm{~d}, J=6.8,3 \mathrm{H}), 0.07(\mathrm{~s}, 3 \mathrm{H}), 0.05(\mathrm{~s}, 3 \mathrm{H})$; ${ }^{13} \mathrm{C}-\mathrm{NMR}\left(125 \mathrm{MHz}, \mathrm{CDCl}_{3}\right) \delta 173.74,134.81,133.62,128.75,126.14,85.42,77.78,65.01$, 55.97, 34.31, 34.01, 29.37, 27.34, 26.16, 23.36, 23.09, 18.58, 13.86, -3.78, -4.96; MS (ESI) 419 $\left[\mathrm{M}+\mathrm{Na}^{+}\right]$; HRMS (FAB) calcd. for $\mathrm{C}_{22} \mathrm{H}_{40} \mathrm{O}_{4} \mathrm{SiNa}\left[\mathrm{M}+\mathrm{Na}^{+}\right]$419.2594, found 419.2601.

Macrolactone 48: To a solution of TBS-macrolactone 47 (179 mg, $0.452 \mathrm{mmol})$ in THF (6 mL) at $\mathrm{rt}$ was added $\mathrm{HF} \cdot$ pyridine (in the beginning: $0.6 \mathrm{~mL}$, after a total of $15 \mathrm{~h}$ : an additional $0.6 \mathrm{~mL}$, after a total of $25 \mathrm{~h}$ : an additional $0.3 \mathrm{~mL}$ ). After stirring for a total of $40 \mathrm{~h}$, the reaction mixture was carefully treated with MeOTMS (12 mL) and concentrated under reduced pressure. Purification of the crude product by FC (hexane/EtOAc 10:1 $\rightarrow$ 5:1) afforded macrolactone 48 $(120 \mathrm{mg}, 94 \%)$ as a white crystalline solid. $[\alpha]_{\mathrm{D}}+115.3^{\circ}\left(\mathrm{c} 1.00, \mathrm{CHCl}_{3}\right)$; IR $\left(\mathrm{CHCl}_{3}\right) 3567$, 3016, 2933, 2858, 1724, 1450, 1387, 1317, 1258, 1145, 1115, 979; ${ }^{1} \mathrm{H}-\mathrm{NMR}\left(500 \mathrm{MHz}, \mathrm{CDCl}_{3}\right)$ $\delta 5.74-5.67(\mathrm{~m}, 2 \mathrm{H}), 5.23(\mathrm{dd}, J=15.7,7.7,1 \mathrm{H}), 4.54(\mathrm{~d}, J=13.1,1 \mathrm{H}), 4.29(\mathrm{~d}, J=13.1,1 \mathrm{H})$, 3.46-3.39 (m, 2H), $3.30(\mathrm{~s}, 3 \mathrm{H}), 2.82-2.77(\mathrm{~m}, 1 \mathrm{H}), 2.44-2.39(\mathrm{~m}, 1 \mathrm{H}), 2.26-2.15(\mathrm{~m}, 2 \mathrm{H}), 2.03-$ $1.97(\mathrm{~m}, 1 \mathrm{H}), 1.74(\mathrm{~d}, J=0.9,3 \mathrm{H}), 1.74-1.70(\mathrm{~m}, 1 \mathrm{H}), 1.60-1.52(\mathrm{~m}, 2 \mathrm{H}), 1.36-1.32(\mathrm{~m}, 1 \mathrm{H})$, $0.93(\mathrm{~d}, J=6.9,3 \mathrm{H}) ;{ }^{13} \mathrm{C}-\mathrm{NMR}\left(125 \mathrm{MHz}, \mathrm{CDCl}_{3}\right) \delta 173.69,135.19,134.39,129.02,127.14$, 83.82, 75.91, 64.76, 56.34, 34.23, 32.06, 29.88, 27.20, 23.40, 23.27, 12.81; MS (ESI) 305 $\left[\mathrm{M}+\mathrm{Na}^{+}\right]$; HRMS (FAB) calcd. for $\mathrm{C}_{16} \mathrm{H}_{26} \mathrm{O}_{4} \mathrm{Na}\left[\mathrm{M}+\mathrm{Na}^{+}\right] 305.1719$, found 305.1729.

Acetylated Macrolactone 49: To a solution of macrolactone 48 (4.5 $\mathrm{mg}, 0.016 \mathrm{mmol}$ ) in $\mathrm{CH}_{2} \mathrm{Cl}_{2}(0.75 \mathrm{~mL})$ at $\mathrm{rt}$ was added DMAP $(6 \mathrm{mg}, 0.048 \mathrm{mmol})$ and $\mathrm{AcCl}(3.5 \mu \mathrm{L}, 0.048 \mathrm{mmol})$. After stirring for $24 \mathrm{~h}$, the reaction mixture was concentrated under reduced pressure to a volume of ca. $0.2 \mathrm{~mL}$. Purification of the residual solution by preparative TLC (hexane/EtOAc 2:1) 
afforded the acetylated macrolactone $49(4 \mathrm{mg}, 76 \%)$ as a colorless oil. ${ }^{1} \mathrm{H}-\mathrm{NMR}(500 \mathrm{MHz}$, $\left.\mathrm{CDCl}_{3}\right) \delta 5.78-5.72(\mathrm{~m}, 1 \mathrm{H}), 5.37(\mathrm{dd}, J=15.7,8.2,1 \mathrm{H}), 5.28(\mathrm{~d}, J=10.0,1 \mathrm{H}), 4.89(\mathrm{dd}, J=8.0$, $3.6,1 \mathrm{H}), 4.56(\mathrm{~d}, J=13.2,1 \mathrm{H}), 4.32(\mathrm{~d}, J=13.2,1 \mathrm{H}), 3.57(\operatorname{app~t}, J=8.1,1 \mathrm{H}), 3.23(\mathrm{~s}, 3 \mathrm{H})$, 3.02-2.97 (m, 1H), 2.46-2.41 (m, 1H), 2.25-2.19 (m, 2H), $2.11(\mathrm{~s}, 3 \mathrm{H}), 2.10-2.05(\mathrm{~m}, 1 \mathrm{H}), 1.81-$ $1.75(\mathrm{~m}, 1 \mathrm{H}), 1.71(\mathrm{~d}, J=0.9,3 \mathrm{H}), 1.61-1.53(\mathrm{~m}, 2 \mathrm{H}), 1.43-1.39(\mathrm{~m}, 1 \mathrm{H}), 0.95(\mathrm{~d}, J=6.9,3 \mathrm{H})$; ${ }^{13} \mathrm{C}-\mathrm{NMR}\left(125 \mathrm{MHz}, \mathrm{CDCl}_{3}\right) \delta 173.61,170.82,135.23,132.14,127.76,82.63,76.83,64.69$, 56.46, 34.30, 32.10, 29.58, 27.02, 23.39, 23.04, 21.10, 14.85; MS (ESI) 347 [M+ $\left.\mathrm{Na}^{+}\right]$; $\mathrm{HRMS}$ (FAB) calcd. for $\mathrm{C}_{18} \mathrm{H}_{28} \mathrm{O}_{5} \mathrm{Na}\left[\mathrm{M}+\mathrm{Na}^{+}\right] 347.1834$, found 347.1848 .

Oxidized Macrolactone 50: To a solution of macrolactone 48 (7 mg, $0.025 \mathrm{mmol})$ in $\mathrm{CH}_{2} \mathrm{Cl}_{2}$ $(1.5 \mathrm{~mL})$ at $\mathrm{rt}$ was added Dess-Martin periodinane $(12 \mathrm{mg}, 0.027 \mathrm{mmol})$. After stirring for $4 \mathrm{~h}$, the reaction mixture was concentrated under reduced pressure to a volume of ca. $0.2 \mathrm{~mL}$. Purification of the residual solution by preparative TLC (hexane/EtOAc 1:1) afforded oxidized macrolactone $50(5 \mathrm{mg}, 72 \%)$ as a colorless oil. ${ }^{1} \mathrm{H}-\mathrm{NMR}\left(500 \mathrm{MHz}, \mathrm{CDCl}_{3}\right) \delta 5.92-5.86(\mathrm{~m}$, $1 \mathrm{H}), 5.73(\mathrm{~d}, \mathrm{~J}=9.9,1 \mathrm{H}), 5.34(\mathrm{dd}, J=15.5,8.0,1 \mathrm{H}), 4.54(\mathrm{~d}, J=11.6,1 \mathrm{H}), 4.37(\mathrm{~d}, J=8.0$, $1 \mathrm{H}), 4.31(\mathrm{~d}, J=11.6,1 \mathrm{H}), 3.71-3.65(\mathrm{~m}, 1 \mathrm{H}), 3.32(\mathrm{~s}, 3 \mathrm{H}), 2.41-2.36(\mathrm{~m}, 1 \mathrm{H}), 2.27-2.21(\mathrm{~m}$, $1 \mathrm{H}), 2.20-2.16(\mathrm{~m}, 1 \mathrm{H}), 2.06-1.99(\mathrm{~m}, 1 \mathrm{H}), 1.81(\mathrm{~s}, 3 \mathrm{H}), 1.68-1.60(\mathrm{~m}, 2 \mathrm{H}), 1.58-1.51(\mathrm{~m}, 1 \mathrm{H})$, $1.41-1.33(\mathrm{~m}, 1 \mathrm{H}), 1.19$ (d, $J=7.1,3 \mathrm{H}) ;{ }^{13} \mathrm{C}-\mathrm{NMR}\left(125 \mathrm{MHz}, \mathrm{CDCl}_{3}\right) \delta 207.91,173.74,138.30$, $130.64,130.42,124.64,86.15,62.75,56.65,41.61,34.04,30.35,26.64,23.40,23.18,18.89$; MS (ESI) $303\left[\mathrm{M}+\mathrm{Na}^{+}\right]$; HRMS (FAB) calcd. for $\mathrm{C}_{16} \mathrm{H}_{24} \mathrm{O}_{4} \mathrm{Na}\left[\mathrm{M}+\mathrm{Na}^{+}\right]$303.1572, found 303.1588.

Hydrolyzed Core 51: To a solution of macrolactone 48 (5 mg, $0.018 \mathrm{mmol})$ in $\mathrm{MeOH}(1.5 \mathrm{~mL})$ at $\mathrm{rt}$ was added $0.5 \mathrm{M} \mathrm{NaOH}(0.3 \mathrm{~mL})$. After stirring for $2 \mathrm{~h}$, the reaction mixture was concentrated under reduced pressure to a volume of ca. $0.5 \mathrm{~mL}$, diluted with $\mathrm{CH}_{2} \mathrm{Cl}_{2}$, and acidified with $1 \mathrm{M} \mathrm{HCl}(2 \mathrm{~mL})$. The organic layer was separated, dried $\left(\mathrm{MgSO}_{4}\right)$, and concentrated under reduced pressure to afford hydrolyzed core 51 (4 mg, 77\%) as a colorless oil. ${ }^{1} \mathrm{H}-\mathrm{NMR}\left(500 \mathrm{MHz}, \mathrm{CDCl}_{3}\right) \delta 5.75-5.70(\mathrm{~m}, 1 \mathrm{H}), 5.34(\mathrm{dd}, J=15.5,8.7,1 \mathrm{H}), 5.23(\mathrm{~d}, J=10.1$, $1 \mathrm{H}), 4.15(\mathrm{~d}, J=11.8,1 \mathrm{H}), 3.97(\mathrm{~d}, J=11.8,1 \mathrm{H}), 3.47-3.44(\mathrm{~m}, 1 \mathrm{H}), 3.29-3.26(\mathrm{~m}, 1 \mathrm{H}), 3.23$ (s, $3 \mathrm{H}), 2.74-2.69(\mathrm{~m}, 1 \mathrm{H}), 2.36(\operatorname{app~t}, J=7.4,2 \mathrm{H}), 2.14(\operatorname{app~q}, J=7.1,2 \mathrm{H}), 1.82(\mathrm{~d}, J=1.2,3 \mathrm{H})$, $1.69-1.63(\mathrm{~m}, 2 \mathrm{H}), 1.51-1.45(\mathrm{~m}, 2 \mathrm{H}), 0.99(\mathrm{~d}, J=6.7,3 \mathrm{H}) ;{ }^{13} \mathrm{C}-\mathrm{NMR}\left(125 \mathrm{MHz}, \mathrm{CDCl}_{3}\right) \delta$ $177.87,136.20,134.96,130.90,127.34,83.24,77.55,61.56,55.65,34.56,33.59,31.81,28.38$, 24.13, 22.00, 16.39; MS (ESI) $323\left[\mathrm{M}+\mathrm{Na}^{+}\right]$; HRMS (FAB) calcd. for $\mathrm{C}_{16} \mathrm{H}_{28} \mathrm{O}_{5} \mathrm{Na}\left[\mathrm{M}+\mathrm{Na}^{+}\right]$ 323.1834 , found 323.1840 .

Allylic Azide 52: To a solution of alcohol 26 (300 mg, $0.954 \mathrm{mmol})$ in toluene (3 $\mathrm{mL})$ at $\mathrm{rt}$ was added DBU (214 $\mu \mathrm{L}, 1.43 \mathrm{mmol})$ and diphenylphosphoryl azide (308 $\mu \mathrm{L}, 1.43 \mathrm{mmol})$. After 
stirring for $5 \mathrm{~h}$, the reaction mixture was treated with saturated aqueous $\mathrm{NH}_{4} \mathrm{Cl}$ solution and diluted with $\mathrm{Et}_{2} \mathrm{O}$. The organic layer was separated and the aqueous layer was extracted with $\mathrm{Et}_{2} \mathrm{O}(3 \mathrm{x})$. The combined organic layers were dried $\left(\mathrm{MgSO}_{4}\right)$ and concentrated under reduced pressure. Purification of the crude product by FC (hexane/EtOAc 30:1) afforded allylic azide 52 (281 mg, 87\%) as a colorless oil. Compound $\mathbf{5 2}$ should be used immediately for the subsequent steps to avoid double bond isomerization. ${ }^{1} \mathrm{H}-\mathrm{NMR}\left(500 \mathrm{MHz}, \mathrm{CDCl}_{3}\right) \delta 5.68-5.60(\mathrm{~m}, 1 \mathrm{H})$, $5.52(\mathrm{~d}, J=10.0,1 \mathrm{H}), 5.32-5.25(\mathrm{~m}, 2 \mathrm{H}), 3.81(\mathrm{~d}, J=13.0,1 \mathrm{H}), 3.66(\mathrm{~d}, J=13.0,1 \mathrm{H}), 3.45(\mathrm{dd}$, $J=7.1,3.0,1 \mathrm{H}), 3.39(\operatorname{app~t}, J=7.5,1 \mathrm{H}), 3.21(\mathrm{~s}, 3 \mathrm{H}), 2.56-2.52(\mathrm{~m}, 1 \mathrm{H}), 1.77(\mathrm{~d}, J=1.2,3 \mathrm{H})$, 0.93-0.90 (m, 12H), 0.06 (s, 3H0, 0.04 (s, 3H); ${ }^{13} \mathrm{C}-\mathrm{NMR}\left(125 \mathrm{MHz}, \mathrm{CDCl}_{3}\right) \delta 135.97,135.19$, 127.27, 118.81, 86.04, 78.39, 56.13, 51.46, 34.40, 26.14, 22.21, 18.53, 14.43, -3.80, -4.77; MS (ESI) $362\left[\mathrm{M}+\mathrm{Na}^{+}\right]$; HRMS (FAB) calcd. for $\mathrm{C}_{17} \mathrm{H}_{33} \mathrm{~N}_{3} \mathrm{O}_{2} \mathrm{SiNa}\left[\mathrm{M}+\mathrm{Na}^{+}\right]$362.2240, found 362.2239 .

Amide 53: To a solution of azide $52(184 \mathrm{mg}, 0.542 \mathrm{mmol})$ in $\mathrm{THF}(5 \mathrm{~mL})$ at $70{ }^{\circ} \mathrm{C}$ was added $\mathrm{PPh}_{3}(249 \mathrm{mg}, 0.949 \mathrm{mmol})$ and $\mathrm{H}_{2} \mathrm{O}(49 \mu \mathrm{L}, 2.71 \mathrm{mmol})$. After stirring for $4 \mathrm{~h}$, the reaction mixture was dried $\left(\mathrm{MgSO}_{4}\right)$ and concentrated under reduced pressure. The residue was dissolved in $\mathrm{CH}_{2} \mathrm{Cl}_{2}(5 \mathrm{~mL})$ and treated with $i$-Pr 2 NEt $(378 \mu \mathrm{L}, 2.17 \mathrm{mmol})$, 6-heptenoic acid $(147 \mu \mathrm{L}, 1.08$ $\mathrm{mmol}$ ), and EDC (207 $\mathrm{mg}, 1.08 \mathrm{mmol})$. After stirring for $30 \mathrm{~min}$, the reaction mixture was concentrated under reduced pressure to a volume of ca. $1 \mathrm{~mL}$. Purification of the residual solution by $\mathrm{FC}\left(\mathrm{CH}_{2} \mathrm{Cl}_{2} \rightarrow \mathrm{CH}_{2} \mathrm{Cl}_{2} / \mathrm{Et}_{2} \mathrm{O} 10: 1\right)$ afforded amide 53 (211 $\left.\mathrm{mg}, 92 \%\right)$ as a colorless oil. ${ }^{1} \mathrm{H}-\mathrm{NMR}\left(500 \mathrm{MHz}, \mathrm{CDCl}_{3}\right) \delta 5.83-5.74(\mathrm{~m}, 1 \mathrm{H}), 5.70-5.64(\mathrm{~m}, 1 \mathrm{H}), 5.41(\mathrm{br} \mathrm{s}, 1 \mathrm{H}), 5.32-$ $5.23(\mathrm{~m}, 3 \mathrm{H}), 5.01-4.93(\mathrm{~m}, 2 \mathrm{H}), 3.86(\mathrm{dd}, J=14.1,5.6,1 \mathrm{H}), 3.79(\mathrm{dd}, J=14.1,5.5,1 \mathrm{H}), 3.47-$ $3.37(\mathrm{~m}, 2 \mathrm{H}), 3.21(\mathrm{~s}, 3 \mathrm{H}), 2.61-2.56(\mathrm{~m}, 1 \mathrm{H}), 2.19-2.15(\mathrm{~m}, 2 \mathrm{H}), 2.08-2.04(\mathrm{~m}, 2 \mathrm{H}), 1.68(\mathrm{~d}, J=$ $1.3,3 \mathrm{H}), 1.67-1.59(\mathrm{~m}, 2 \mathrm{H}), 1.45-1.38(\mathrm{~m}, 2 \mathrm{H}), 0.91-0.89(\mathrm{~m}, 12 \mathrm{H}), 0.06(\mathrm{~s}, 3 \mathrm{H}), 0.02(\mathrm{~s}, 3 \mathrm{H})$; ${ }^{13} \mathrm{C}-\mathrm{NMR}\left(125 \mathrm{MHz}, \mathrm{CDCl}_{3}\right) \delta 172.79,138.44,135.10,133.94,129.82,118.66,114.66,86.01$, 78.22, 56.11, 39.84, 36.65, 34.26, 33.44, 28.52, 26.11, 25.25, 21.93, 18.50, 14.76, -3.83, -4.77; MS (ESI) $446\left[\mathrm{M}+\mathrm{Na}^{+}\right]$; HRMS (FAB) calcd. for $\mathrm{C}_{24} \mathrm{H}_{45} \mathrm{NO}_{3} \mathrm{SiNa}\left[\mathrm{M}+\mathrm{Na}^{+}\right]$446.3066, found 446.3065 .

TBS-Macrolactam 54: To a solution of amide $53(105 \mathrm{mg}, 0.248 \mathrm{mmol})$ in refluxing toluene $(350 \mathrm{~mL})$ was added Grubbs-II catalyst $16(42 \mathrm{mg}, 0.050 \mathrm{mmol})$. After stirring for $15 \mathrm{~min}$, the reaction mixture was cooled to $\mathrm{rt}$ and filtered through a silica plug (hexane/EtOAc 1:2). Purification of the crude product by FC (hexane/EtOAc 2:1) afforded TBS-macrolactam 54 (59 $\mathrm{mg}, 60 \%)$ as a colorless oil. ${ }^{1} \mathrm{H}-\mathrm{NMR}\left(500 \mathrm{MHz}, \mathrm{CDCl}_{3}\right) \delta 5.81-5.75(\mathrm{~m}, 1 \mathrm{H}), 5.46(\mathrm{~d}, J=9.9$, $1 \mathrm{H}), 5.36$ (dd, $J=15.9,6.0,1 \mathrm{H}), 5.30$ (br s, $1 \mathrm{H}), 3.77$ (dd, $J=13.9,3.5,1 \mathrm{H}), 3.66$ (dd, $J=13.9$, 5.4, 1H), 3.48-3.44 (m, 2H), $3.21(\mathrm{~s}, 3 \mathrm{H}), 2.63-2.58(\mathrm{~m}, 1 \mathrm{H}), 2.21-2.08(\mathrm{~m}, 3 \mathrm{H}), 2.05-1.98(\mathrm{~m}$, 
$1 \mathrm{H}), 1.73(\mathrm{~d}, J=1.1,3 \mathrm{H}), 1.65-1.49(\mathrm{~m}, 3 \mathrm{H}), 1.39-1.32(\mathrm{~m}, 1 \mathrm{H}), 0.92-0.90(\mathrm{~m}, 12 \mathrm{H}), 0.07(\mathrm{~s}$, $3 \mathrm{H}), 0.05(\mathrm{~s}, 3 \mathrm{H}) ;{ }^{13} \mathrm{C}-\mathrm{NMR}\left(125 \mathrm{MHz}, \mathrm{CDCl}_{3}\right) \delta 173.26,134.11,133.90,129.03,128.54,84.80$, 77.46, 56.29, 41.41, 36.01, 34.48, 29.59, 27.45, 26.11, 24.68, 24.32, 18.56, 14.77, -3.92, -4.93; MS (ESI) $418\left[\mathrm{M}+\mathrm{Na}^{+}\right]$; HRMS (FAB) calcd. for $\mathrm{C}_{22} \mathrm{H}_{41} \mathrm{NO}_{3} \mathrm{SiNa}\left[\mathrm{M}+\mathrm{Na}^{+}\right]$418.2753, found 418.2752 .

Macrolactam 55: To a solution of TBS-macrolactam 54 (91 mg, $0.230 \mathrm{mmol})$ in THF (3 mL) at rt was added $\mathrm{HF} \bullet$ pyridine (in the beginning: $0.4 \mathrm{~mL}$, after a total of $18 \mathrm{~h}$ : an additional $0.15 \mathrm{~mL}$ ). After stirring for a total of $21 \mathrm{~h}$, the reaction mixture was carefully treated with MeOTMS (5 mL) and concentrated under reduced pressure. Purification of the crude product by FC (hexane/EtOAc $1: 1 \rightarrow 1: 2)$ afforded macrolactam $55(52 \mathrm{mg}, 81 \%)$ as a colorless oil. $[\alpha]_{\mathrm{D}}$ $+101.3^{\circ}$ (c 1.00, $\left.\mathrm{CHCl}_{3}\right)$; IR $\left(\mathrm{CHCl}_{3}\right)$ 3566, 3444, 3021, 2936, 2828, 1658, 1504, 1478, 1398, 1229, 1088, 979; ${ }^{1} \mathrm{H}-\mathrm{NMR}\left(500 \mathrm{MHz}, \mathrm{CDCl}_{3}\right) \delta 5.79-5.73(\mathrm{~m}, 1 \mathrm{H}), 5.66(\mathrm{~d}, J=10.2,1 \mathrm{H}), 5.24$ $(\mathrm{dd}, J=15.8,7.5,1 \mathrm{H}), 5.12$ (br s, $1 \mathrm{H}), 3.91(\mathrm{dd}, J=13.7,4.1,1 \mathrm{H}), 3.50-3.46(\mathrm{~m}, 2 \mathrm{H}), 3.34-3.30$ (m, 1H), $3.31(\mathrm{~s}, 3 \mathrm{H}), 2.89$ (br s, 1H), 2.56-2.52 (m, 1H), 2.32-2.25 (m, 2H), 2.16-2.11 (m, 1H), 1.96-1.89 (m, 1H), $1.77(\mathrm{~d}, J=1.1,3 \mathrm{H}), 1.73-1.51(\mathrm{~m}, 3 \mathrm{H}), 1.37-1.32(\mathrm{~m}, 1 \mathrm{H}), 0.94(\mathrm{~d}, J=6.9$, $3 \mathrm{H}) ;{ }^{13} \mathrm{C}-\mathrm{NMR}\left(125 \mathrm{MHz}, \mathrm{CDCl}_{3}\right) \delta 173.36,135.52,133.77,129.89,128.73,83.21,76.38,56.45$, 41.40, 35.95, 32.27, 29.86, 27.00, 24.82, 24.42, 13.03; MS (ESI) 304 [M+Na ${ }^{+}$; HRMS (FAB) calcd. for $\mathrm{C}_{16} \mathrm{H}_{27} \mathrm{NO}_{3} \mathrm{Na}\left[\mathrm{M}+\mathrm{Na}^{+}\right]$304.1888, found 304.1889.

Allylic Bromide 56: To a solution of alcohol 26 (325 mg, $1.03 \mathrm{mmol})$ in $\mathrm{CH}_{2} \mathrm{Cl}_{2}(10 \mathrm{~mL})$ at $\mathrm{rt}$ was added solid supported $\mathrm{PPh}_{3}$ (excess until reaction complete) and $\mathrm{CBr}_{4}$ (478 mg, $1.44 \mathrm{mmol}$ ). After stirring for $15 \mathrm{~min}$, the reaction mixture was filtered through a cotton plug and concentrated under reduced pressure to yield the allylic bromide 56. ${ }^{1} \mathrm{H}-\mathrm{NMR}\left(500 \mathrm{MHz}, \mathrm{CDCl}_{3}\right) \delta 5.67$ (ddd, $J=17.2,10.3,8.3,1 \mathrm{H}), 5.41(\mathrm{dd}, J=10.0,0.9,1 \mathrm{H}), 5.31(\mathrm{dd}, J=10.3,2.0,1 \mathrm{H}), 5.27(\mathrm{dt}, J=$ $17.2,1.0,1 \mathrm{H}), 3.94(\mathrm{~s}, 2 \mathrm{H}), 3.55(\mathrm{dd}, J=7.2,3.0,1 \mathrm{H}), 3.39(\operatorname{app~t}, J=7.4,1 \mathrm{H}), 3.21(\mathrm{~s}, 3 \mathrm{H})$, 2.63-2.56 (m, 1H), $1.81(\mathrm{~d}, J=0.9,3 \mathrm{H}), 0.93(\mathrm{~d}, J=6.4,3 \mathrm{H}), 0.91(\mathrm{~s}, 9 \mathrm{H}), 0.06(\mathrm{~s}, 3 \mathrm{H}), 0.03$ (s, $3 \mathrm{H}) ;{ }^{13} \mathrm{C}-\mathrm{NMR}\left(125 \mathrm{MHz}, \mathrm{CDCl}_{3}\right) \delta 136.35,135.20,129.64,118.82,86.09,77.57,56.15,34.68$, $32.34,26.13,21.91,18.50,13.54,-3.83,-4.82$.

$\beta$-Ketosulfone 57: To a solution of methyl phenyl sulfone (1.43 g, $9.14 \mathrm{mmol})$ in THF (15 mL) at $-15^{\circ} \mathrm{C}$ was added $\mathrm{BuLi}(6.28 \mathrm{~mL}, 10.0 \mathrm{mmol}, 1.6 \mathrm{M}$ in hexane). After stirring for $30 \mathrm{~min}$, the reaction mixture was cooled to $-78{ }^{\circ} \mathrm{C}$ and ethyl 6-heptenoate $(802 \mu \mathrm{L}, 4.57 \mathrm{mmol})$ was added. The reaction mixture was warmed to $\mathrm{rt}$ and then treated with saturated aqueous $\mathrm{NH}_{4} \mathrm{Cl}$ solution. The organic layer was separated and the aqueous layer was extracted with EtOAc (3x). The combined organic layers were dried $\left(\mathrm{MgSO}_{4}\right)$ and concentrated under reduced pressure. 
Purification of the crude product by FC (hexane/EtOAc 5:1) afforded $\beta$-ketosulfone 57 (1.12 g, $92 \%)$ as a white solid. ${ }^{1} \mathrm{H}-\mathrm{NMR}\left(500 \mathrm{MHz}, \mathrm{CDCl}_{3}\right) \delta 7.88-7.86(\mathrm{~m}, 2 \mathrm{H}), 7.68-7.65(\mathrm{~m}, 1 \mathrm{H})$, 7.58-7.54 (m, 2H), 5.79-5.71 (m, 1H), 5.00-4.92 (m, 2H), $4.14(\mathrm{~s}, 2 \mathrm{H}), 2.70-2.67(\mathrm{~m}, 2 \mathrm{H}), 2.05-$ $2.00(\mathrm{~m}, 2 \mathrm{H}), 1.58-1.52(\mathrm{~m}, 2 \mathrm{H}), 1.38-1.32(\mathrm{~m}, 2 \mathrm{H}) ;{ }^{13} \mathrm{C}-\mathrm{NMR}\left(125 \mathrm{MHz}, \mathrm{CDCl}_{3}\right) \delta 197.99$, 138.14, 134.19, 129.25, 129.06, 128.17, 114.73, 66.70, 44.12, 33.26, 27.85, 22.42; MS (ESI) 289 $\left[\mathrm{M}+\mathrm{Na}^{+}\right]$; HRMS (FAB) calcd. for $\mathrm{C}_{14} \mathrm{H}_{18} \mathrm{O}_{3} \mathrm{SNa}\left[\mathrm{M}+\mathrm{Na}^{+}\right] 289.0874$, found 289.0882.

Ketone 58: To a solution of $\beta$-ketosulfone $57(685 \mathrm{mg}, 2.57 \mathrm{mmol})$ in toluene $(5 \mathrm{~mL})$ at $\mathrm{rt}$ was added DBU $(385 \mu \mathrm{L}, 2.57 \mathrm{mmol})$. After stirring for $50 \mathrm{~min}$, a solution of crude allylic bromide 56 in toluene $(5 \mathrm{~mL})$ was added and the reaction mixture was stirred for another $45 \mathrm{~min}$. The reaction mixture was concentrated under reduced pressure to a volume of ca. $1 \mathrm{~mL}$ and the residual solution was filtered through a silica plug (hexane/EtOAc 7:1). To a solution of crude alkylated sulfone in $\mathrm{MeOH}(10 \mathrm{~mL})$ at $\mathrm{rt}$ was added $\mathrm{Na}_{2} \mathrm{HPO}_{4}(366 \mathrm{mg}, 2.57 \mathrm{mmol})$ and 10\% $\mathrm{Na} / \mathrm{Hg}$ (474 mg, ca. $2.06 \mathrm{mmol}$ ). After stirring for $3 \mathrm{~h}$, the reaction mixture was filtered through a cotton plug and $\mathrm{H}_{2} \mathrm{O}$ was added to the filtrate. The organic layer was separated and the aqueous layer was extracted with $\mathrm{CH}_{2} \mathrm{Cl}_{2}(3 \mathrm{x})$. The combined organic layers were dried $\left(\mathrm{MgSO}_{4}\right)$ and concentrated under reduced pressure. Purification of the crude product by FC (hexane/EtOAc $30: 1)$ afforded ketone $58(258 \mathrm{mg}, 61 \%)$ as a colorless oil. ${ }^{1} \mathrm{H}-\mathrm{NMR}\left(500 \mathrm{MHz}, \mathrm{CDCl}_{3}\right) \delta 5.82-$ $5.75(\mathrm{~m}, 1 \mathrm{H}), 5.67-5.60(\mathrm{~m}, 1 \mathrm{H}), 5.29-5.18(\mathrm{~m}, 3 \mathrm{H}), 5.02-4.93(\mathrm{~m}, 2 \mathrm{H}), 3.41(\mathrm{dd}, J=7.2,2.8$, $1 \mathrm{H}), 3.37(\operatorname{app~t}, J=7.6,1 \mathrm{H}), 3.20(\mathrm{~s}, 3 \mathrm{H}), 2.52-2.47(\mathrm{~m}, 1 \mathrm{H}), 2.44-2.38(\mathrm{~m}, 4 \mathrm{H}), 2.28-2.18(\mathrm{~m}$, 2H), $2.06(\operatorname{app~q,~} J=7.1,2 \mathrm{H}), 1.64(\mathrm{~d}, J=1.2,3 \mathrm{H}), 1.62-1.56(\mathrm{~m}, 2 \mathrm{H}), 1.41-1.35(\mathrm{~m}, 2 \mathrm{H}), 0.90$ $(\mathrm{s}, 9 \mathrm{H}), 0.87(\mathrm{~d}, J=6.7,3 \mathrm{H}), 0.05(\mathrm{~s}, 3 \mathrm{H}), 0.01(\mathrm{~s}, 3 \mathrm{H}) ;{ }^{13} \mathrm{C}-\mathrm{NMR}\left(125 \mathrm{MHz}, \mathrm{CDCl}_{3}\right) \delta 210.57$, 138.45, 135.30, 131.81, 131.30, 118.53, 114.64, 86.27, 78.61, 56.10, 42.64, 41.23, 34.05, 33.50, 28.46, 26.16, 26.12, 23.27, 23.11, 18.55, 14.05, -3.79, -4.79; MS (ESI) 445 [M+Na ${ }^{+}$; $\mathrm{HRMS}$ (FAB) calcd. for $\mathrm{C}_{25} \mathrm{H}_{46} \mathrm{O}_{3} \mathrm{SiNa}\left[\mathrm{M}+\mathrm{Na}^{+}\right]$445.3114, found 445.3095.

TBS-Macroketone 59: To a solution of ketone 58 (258 $\mathrm{mg}, 0.610 \mathrm{mmol})$ in refluxing toluene $(1200 \mathrm{~mL})$ was added Grubbs-II catalyst $16(104 \mathrm{mg}, 0.122 \mathrm{mmol})$. After stirring for $15 \mathrm{~min}$, the reaction mixture was cooled to $\mathrm{rt}$ and filtered through a silica plug (hexane/EtOAc 2:1). Purification of the crude product by FC (hexane/EtOAc 20:1) afforded TBS-macroketone 59 (194 $\mathrm{mg}, 81 \%)$ as a colorless oil. ${ }^{1} \mathrm{H}-\mathrm{NMR}\left(500 \mathrm{MHz}, \mathrm{CDCl}_{3}\right) \delta 5.67-5.61(\mathrm{~m}, 1 \mathrm{H}), 5.32(\mathrm{dd}, J=$ $15.7,6.7,1 \mathrm{H}), 5.26(\mathrm{dd}, J=9.8,0.9,1 \mathrm{H}), 3.41-3.36(\mathrm{~m}, 2 \mathrm{H}), 3.21(\mathrm{~s}, 3 \mathrm{H}), 2.55-2.49(\mathrm{~m}, 1 \mathrm{H})$, 2.46-2.41 (m, 1H), 2.39-2.33 (m, 1H), 2.32-2.18 (m, 5H), 2.14-2.10 (m, 1H), 1.68-1.63 (m, 1H), $1.67(\mathrm{~d}, J=1.3,3 \mathrm{H}), 1.62-1.53(\mathrm{~m}, 2 \mathrm{H}), 1.51-1.46(\mathrm{~m}, 1 \mathrm{H}), 0.90(\mathrm{~s}, 9 \mathrm{H}), 0.89(\mathrm{~d}, J=6.8,3 \mathrm{H})$, $0.05(\mathrm{~s}, 3 \mathrm{H}), 0.00(\mathrm{~s}, 3 \mathrm{H}) ;{ }^{13} \mathrm{C}-\mathrm{NMR}\left(125 \mathrm{MHz}, \mathrm{CDCl}_{3}\right) \delta 211.96,133.10,131.91,131.68$, $129.87,84.77,79.32,56.24,41.44,40.91,34.32$, 30.25, 28.74, 26.84, 26.15, 23.15, 22.85, 18.60, 
12.78, -3.85, -5.03; MS (ESI) $417\left[\mathrm{M}+\mathrm{Na}^{+}\right]$; HRMS (FAB) calcd. for $\mathrm{C}_{23} \mathrm{H}_{42} \mathrm{O}_{3} \mathrm{SiNa}\left[\mathrm{M}+\mathrm{Na}^{+}\right]$ 417.2801, found 417.2819.

Macroketone 60: To a solution of TBS-macroketone 59 (194 mg, $0.492 \mathrm{mmol})$ in THF (15 mL) at $\mathrm{rt}$ was added $\mathrm{HF} \bullet$ pyridine $(3.5 \mathrm{~mL})$. After stirring for $15 \mathrm{~h}$, the reaction mixture was carefully treated with MeOTMS $(25 \mathrm{~mL})$ and concentrated under reduced pressure. Purification of the crude product by FC (hexane/EtOAc 10:1 $\rightarrow$ 4:1) afforded macroketone $\mathbf{6 0}(124 \mathrm{mg}, 90 \%)$ as a colorless oil. $[\alpha]_{\mathrm{D}}+77.6^{\circ}\left(c 0.50, \mathrm{CHCl}_{3}\right)$; IR (neat) 3566, 3022, 3015, 2975, 2937, 2879, 1700, 1448, 1384, 1237, 1109, 1085, 979; ${ }^{1} \mathrm{H}-\mathrm{NMR}\left(500 \mathrm{MHz}, \mathrm{CDCl}_{3}\right) \delta 5.72$ (ddd, $J=15.0,8.5,6.0$, $1 \mathrm{H}), 5.37$ (dd, $J=10.0,0.9,1 \mathrm{H}$ ), 5.31 (dd, $J=15.6,7.8,1 \mathrm{H}$ ), 3.47 (app t, $J=8.5,1 \mathrm{H}$ ), 3.36 (dd, $J=9.2,1.2,1 \mathrm{H}), 3.31$ (s, 3H), 2.78 (br s, $1 \mathrm{H}), 2.51-2.45$ (m, 2H), 2.37-2.32 (m, 2H), 2.26-2.16 $(\mathrm{m}, 5 \mathrm{H}), 1.69(\mathrm{~d}, J=1.3,3 \mathrm{H}), 1.68-1.59(\mathrm{~m}, 2 \mathrm{H}), 1.55-1.50(\mathrm{~m}, 2 \mathrm{H}), 0.95(\mathrm{~d}, J=6.8,3 \mathrm{H}) ;{ }^{13} \mathrm{C}-$ NMR $\left(125 \mathrm{MHz}, \mathrm{CDCl}_{3}\right) \delta 212.10,135.23,132.91,130.26,129.22,83.69,77.62,56.45,42.08$, 40.67, 32.57, 30.33, 28.57, 27.01, 23.22, 23.14, 12.61; MS (ESI) $303\left[\mathrm{M}+\mathrm{Na}^{+}\right]$; HRMS (FAB) calcd. for $\mathrm{C}_{17} \mathrm{H}_{28} \mathrm{O}_{3} \mathrm{Na}\left[\mathrm{M}+\mathrm{Na}^{+}\right]$303.1936, found 303.1938 .

Secondary Alcohols 61 and 62: To a solution of alcohol 26 (360 mg, $1.15 \mathrm{mmol})$ in $\mathrm{CH}_{2} \mathrm{Cl}_{2}(5$ $\mathrm{mL}$ ) at $\mathrm{rt}$ was added Dess-Martin periodinane $(970 \mathrm{mg}, 2.29 \mathrm{mmol})$. After stirring for $1 \mathrm{~h}$, the reaction mixture was treated with saturated aqueous $\mathrm{Na}_{2} \mathrm{~S}_{2} \mathrm{O}_{3}$ solution and saturated aqueous $\mathrm{NaHCO}_{3}$ solution. The organic layer was separated and the aqueous layer was extracted with $\mathrm{CH}_{2} \mathrm{Cl}_{2}(3 \mathrm{x})$. The combined organic layers were dried $\left(\mathrm{Na}_{2} \mathrm{SO}_{4}\right)$ and concentrated under reduced pressure to afford the corresponding aldehyde 27. Crude product 27 was dissolved in $\mathrm{Et}_{2} \mathrm{O}$ (12 $\mathrm{mL})$ and $i-\mathrm{PrMgCl}\left(2.90 \mathrm{~mL}, 5.80 \mathrm{mmol}, 2 \mathrm{M}\right.$ in THF) was added at $-78{ }^{\circ} \mathrm{C}$. After stirring for 5 $\mathrm{h}$, the reaction mixture was treated with saturated aqueous $\mathrm{NH}_{4} \mathrm{Cl}$ solution. The organic layer was separated and the aqueous layer was extracted with EtOAc (3x). The combined organic layers were dried $\left(\mathrm{MgSO}_{4}\right)$ and concentrated under reduced pressure. Purification of the crude product by FC (toluene/EtOAc 19:1) afforded $(S)$-secondary alcohol $61(186 \mathrm{mg}, 50 \%)$ and $(R)$ secondary alcohol 62 (134 $\mathrm{mg}, 36 \%)$ as colorless oils.

(S)-Secondary Alcohol 61: IR (neat) 3476, 2956, 2929, 2884, 2857, 1471, 1462, 1378, 1251, 1127, 1096, 1080, 1032, 1006; ${ }^{1} \mathrm{H}-\mathrm{NMR}\left(500 \mathrm{MHz}, \mathrm{CDCl}_{3}\right) \delta 5.78-5.68(\mathrm{~m}, 1 \mathrm{H}), 5.31-5.23(\mathrm{~m}$, $3 \mathrm{H}), 3.98(\mathrm{~d}, J=9.8,1 \mathrm{H}), 3.51-3.48(\mathrm{~m}, 2 \mathrm{H}), 3.24(\mathrm{~s}, 3 \mathrm{H}), 2.73-2.68(\mathrm{~m}, 1 \mathrm{H}), 1.78-1.69(\mathrm{~m}, 1 \mathrm{H})$, $1.66(\mathrm{~s}, 3 \mathrm{H}), 1.60(\mathrm{br} \mathrm{s}, 1 \mathrm{H}), 1.03(\mathrm{~d}, J=6.4,3 \mathrm{H}), 0.91$ (s, 9H), 0.89 (d, $J=6.0,3 \mathrm{H}), 0.73$ (d, $J=$ 6.9, 3H), 0.07 (s, 3H), 0.05 (s, 3H); ${ }^{13} \mathrm{C}-\mathrm{NMR}\left(125 \mathrm{MHz}, \mathrm{CDCl}_{3}\right) \delta 135.37,134.58,133.16$, 118.24, 85.74, 77.85, 75.73, 56.23, 33.64, 30.96, 26.13, 19.51, 18.93, 18.48, 17.56, 15.66, -3.86, -4.57; MS (ESI) $379\left[\mathrm{M}+\mathrm{Na}^{+}\right]$; HRMS (FAB) calcd. for $\mathrm{C}_{20} \mathrm{H}_{40} \mathrm{O}_{3} \mathrm{SiNa}\left[\mathrm{M}+\mathrm{Na}^{+}\right]$379.2644, found 379.2663 . 
(R)-Secondary Alcohol 62: IR (neat) 3378, 2955, 2931, 2919, 2872, 1466, 1455, 1378, 1249 , 1119, 1096, 1079, 1026; ${ }^{1} \mathrm{H}-\mathrm{NMR}\left(500 \mathrm{MHz}, \mathrm{CDCl}_{3}\right) \delta 5.59$ (ddd, $\left.J=17.3,10.3,8.2,1 \mathrm{H}\right), 5.40$ $(\mathrm{dd}, J=10.3,1.4,1 \mathrm{H}), 5.31(\mathrm{dd}, J=10.2,1.5,1 \mathrm{H}), 5.27(\mathrm{dd}, J=17.3,1.4,1 \mathrm{H}), 3.97(\mathrm{~d}, J=9.2$, $1 \mathrm{H}), 3.43$ (dd, $J=7.4,2.2,1 \mathrm{H}), 3.37$ (app t, $J=8.1,1 \mathrm{H}), 3.21(\mathrm{~s}, 3 \mathrm{H}), 2.67-2.62(\mathrm{~m}, 1 \mathrm{H}), 1.80-$ $1.73(\mathrm{~m}, 1 \mathrm{H}), 1.67$ (d, $J=1.5,3 \mathrm{H}), 1.37($ br s, $1 \mathrm{H}), 1.04(\mathrm{~d}, J=6.5,3 \mathrm{H}), 0.91(\mathrm{~s}, 9 \mathrm{H}), 0.90(\mathrm{~d}, J=$ 6.6, 3H), $0.76(\mathrm{~d}, J=6.6,3 \mathrm{H}), 0.05(\mathrm{~s}, 3 \mathrm{H}), 0.02(\mathrm{~s}, 3 \mathrm{H}) ;{ }^{13} \mathrm{C}-\mathrm{NMR}\left(125 \mathrm{MHz}, \mathrm{CDCl}_{3}\right) \delta 135.02$, 134.13, 133.88, 118.86, 86.39, 78.35, 75.92, 56.06, 33.16, 31.52, 26.15, 19.52, 19.34, 18.59, 17.68, 13.74, -3.80, -4.84; MS (ESI) $379\left[\mathrm{M}+\mathrm{Na}^{+}\right]$; HRMS (FAB) calcd. for $\mathrm{C}_{20} \mathrm{H}_{40} \mathrm{O}_{3} \mathrm{SiNa}$ $\left[\mathrm{M}+\mathrm{Na}^{+}\right]$379.2644, found 379.2643.

(S)-Isopropyl Ester 63: To a solution of alcohol $61(55 \mathrm{mg}, 0.154 \mathrm{mmol})$ in toluene $(0.4 \mathrm{~mL})$ at rt was added pyridine $(62 \mu \mathrm{L}, 0.772 \mathrm{mmol})$ and the mixed anhydride ${ }^{11}$ of 6 -heptenoic acid and 2,4,6-trichlorobenzoyl chloride ( $1.5 \mathrm{~mL}, 0.75 \mathrm{mmol}, 0.50 \mathrm{M}$ in toluene). After stirring $15 \mathrm{~h}$, the reaction mixture was directly loaded onto a silica column and purified by FC (toluene) to afford (S)-isopropyl ester $\mathbf{6 3}$ (54 mg, 75\%) as a colorless oil. IR (neat) 2928, 2830, 1732, 1470, 1378, 1247, 1125, 1096, 1032; ${ }^{1} \mathrm{H}-\mathrm{NMR}\left(500 \mathrm{MHz}, \mathrm{CDCl}_{3}\right) \delta 5.81-5.76(\mathrm{~m}, 2 \mathrm{H}), 5.41(\mathrm{~d}, J=10.4$, $1 \mathrm{H}), 5.31(\mathrm{dd}, J=10.3,2.0,1 \mathrm{H}), 5.24(\operatorname{app~d}, J=17.2,1 \mathrm{H}), 5.17$ (app d, $J=9.9,1 \mathrm{H}), 5.00$ (app d, $J=17.1,1 \mathrm{H}), 4.94(\mathrm{~d}, J=5.8,1 \mathrm{H}), 3.59(\mathrm{dd}, J=8.0,1.8,1 \mathrm{H}), 3.32(\operatorname{app~t}, J=8.4,1 \mathrm{H}), 3.20$ (s, 3H), 2.73-2.68 (m, 1H), 2.28 (app t, $J=7.5,2 \mathrm{H}), 2.08-2.04(\mathrm{~m}, 2 \mathrm{H}), 1.91-1.88(\mathrm{~m}, 1 \mathrm{H}), 1.66-$ $1.59(\mathrm{~m}, 3 \mathrm{H}), 1.61(\mathrm{~s}, 3 \mathrm{H}), 1.44-1.41(\mathrm{~m}, 1 \mathrm{H}), 0.91(\mathrm{~d}, J=8.3,3 \mathrm{H}), 0.90(\mathrm{~s}, 9 \mathrm{H}), 0.84(\mathrm{~d}, J=6.7$, $3 \mathrm{H}), 0.77(\mathrm{~d}, J=6.9,3 \mathrm{H}), 0.04(\mathrm{~s}, 3 \mathrm{H}),-0.02(\mathrm{~s}, 3 \mathrm{H}) ;{ }^{13} \mathrm{C}-\mathrm{NMR}\left(125 \mathrm{MHz}, \mathrm{CDCl}_{3}\right) \delta 172.48$, 138.46, 135.43, 135.32, 129.62, 118.71, 114.62, 86.92, 78.07, 77.52, 77.34, 55.83, 34.42, 33.39, $33.27,29.71,28.38,26.22,24.66,19.22,18.53,18.36,12.69,-3.80,-4.96$; MS (ESI) 489 $\left[\mathrm{M}+\mathrm{Na}^{+}\right]$; HRMS (FAB) calcd. for $\mathrm{C}_{27} \mathrm{H}_{50} \mathrm{O}_{4} \mathrm{SiNa}\left[\mathrm{M}+\mathrm{Na}^{+}\right]$489.3376, found 489.3362.

(R)-Isopropyl Ester 66: Preparation performed exactly as for $(S)$-isopropyl ester 63, affording $(R)$-isopropyl ester 66 in 70\% yield. IR (neat) 2956, 2928, 2856, 1732, 1469, 1462, 1370, 1249, 1129, 1032; ${ }^{1} \mathrm{H}-\mathrm{NMR}\left(500 \mathrm{MHz}, \mathrm{CDCl}_{3}\right) \delta 5.81-5.74(\mathrm{~m}, 1 \mathrm{H}), 5.61$ (ddd, $J=17.6,10.6,7.6$, $1 \mathrm{H}), 5.45(\mathrm{~d}, J=9.4,1 \mathrm{H}), 5.33(\mathrm{dd}, J=10.4,1.9,1 \mathrm{H}), 5.29(\mathrm{dd}, J=17.0,1.9,1 \mathrm{H}), 5.15(\operatorname{app} \mathrm{d}, J$ $=9.8,1 \mathrm{H}), 4.99(\mathrm{dd}, J=17.0,1.9,1 \mathrm{H}), 4.95-4.93(\mathrm{~m}, 1 \mathrm{H}), 3.40-3.38(\mathrm{~m}, 2 \mathrm{H}), 3.21(\mathrm{~s}, 3 \mathrm{H}), 2.82-$ $2.76(\mathrm{~m}, 1 \mathrm{H}), 2.29(\operatorname{app~t}, J=7.5,2 \mathrm{H}), 2.08-2.03(\mathrm{~m}, 2 \mathrm{H}), 1.97-1.90(\mathrm{~m}, 2 \mathrm{H}), 1.64-1.61(\mathrm{~m}, 1 \mathrm{H})$, $1.61(\mathrm{~d}, J=1.3,3 \mathrm{H}), 1.43-1.36(\mathrm{~m}, 2 \mathrm{H}), 0.92(\mathrm{~d}, J=6.6,3 \mathrm{H}), 0.91(\mathrm{~s}, 9 \mathrm{H}), 0.89(\mathrm{~d}, J=6.6,3 \mathrm{H})$, $0.79(\mathrm{~d}, J=6.0,3 \mathrm{H}), 0.05(\mathrm{~s}, 3 \mathrm{H}), 0.01(\mathrm{~s}, 3 \mathrm{H}) ;{ }^{13} \mathrm{C}-\mathrm{NMR}\left(125 \mathrm{MHz}, \mathrm{CDCl}_{3}\right) \delta 172.82,138.47$, 135.59 , 134.68, 129.61, 118.97, 114.63, 86.41, 78.32, 77.72, 56.06, 34.42, 33.65, 33.38, 29.71,

\footnotetext{
${ }^{11}$ The preparation of the mixed anhydride of 6-heptenoic acid and 2,4,6-trichlorobenzoyl chloride was performed exactly as for the mixed anhydride of 2,6-heptadienoic acid and 2,4,6-trichlorobenzoyl chloride (see above).
} 
$28.35,26.18,24.58,19.38,18.96,18.61,18.19,12.89,-3.76,-4.91 ; \mathrm{MS}$ (ESI) $489\left[\mathrm{M}+\mathrm{Na}^{+}\right]$; HRMS (FAB) calcd. for $\mathrm{C}_{27} \mathrm{H}_{50} \mathrm{O}_{4} \mathrm{SiNa}\left[\mathrm{M}+\mathrm{Na}^{+}\right]$489.3376, found 489.3363.

(S)-Isopropyl Macrolactone 65: To a solution of (S)-isopropyl ester 63 (25 $\mathrm{mg}, 0.053 \mathrm{mmol})$ in refluxing toluene $(100 \mathrm{~mL})$ was added Grubbs-II catalyst $16(9 \mathrm{mg}, 0.0107 \mathrm{mmol})$. After stirring for $15 \mathrm{~min}$, the reaction mixture was cooled to $\mathrm{rt}$ and filtered through a silica plug (hexane/EtOAc 1:3). After evaporation of the solvent, crude product 64 was dissolved in THF (3 mL) and treated with HF•pyridine $(0.75 \mathrm{~mL})$ at $\mathrm{rt}$. After stirring for $40 \mathrm{~h}$, the reaction mixture was carefully treated with MeOTMS (6 mL) and concentrated under reduced pressure. Purification of the crude product by $\mathrm{FC}\left(\mathrm{CH}_{2} \mathrm{Cl}_{2} /\right.$ EtOAc 9:1) afforded $(S)$-isopropyl macrolactone 65 (12 $\left.\mathrm{mg}, 65 \%\right)$ as a colorless oil. $[\alpha]_{\mathrm{D}}+25.1^{\circ}\left(c 0.32, \mathrm{CHCl}_{3}\right)$; IR (neat) $3479,2967,2926,2876,1724,1448$, 1373, 1257, 1237, 1091; ${ }^{1} \mathrm{H}-\mathrm{NMR}\left(500 \mathrm{MHz}, \mathrm{CDCl}_{3}\right) \delta 5.70(\mathrm{ddd}, J=15.4,8.5,5.3,1 \mathrm{H}), 5.33$ $(\mathrm{dd}, J=10.0,0.9,1 \mathrm{H}), 5.30(\mathrm{~d}, J=7.0,1 \mathrm{H}), 5.19-5.13(\mathrm{~m}, 1 \mathrm{H}), 3.40-3.30(\mathrm{~m}, 2 \mathrm{H}), 3.28(\mathrm{~s}, 3 \mathrm{H})$, 2.99-2.95 (m, 1H), 2.76 (br s, 1H), 2.36-2.24 (m, 2H), 2.20-2.08 (m, 2H), 1.99 (app dt, $J=7.0$, $6.9,1 \mathrm{H}), 1.69(\mathrm{~d}, J=1.3,3 \mathrm{H}), 1.62-1.52(\mathrm{~m}, 4 \mathrm{H}), 0.94(\mathrm{~d}, J=7.0,3 \mathrm{H}), 0.91(\mathrm{~d}, J=6.6,3 \mathrm{H})$, $0.86(\mathrm{~d}, J=6.9,3 \mathrm{H}) ;{ }^{13} \mathrm{C}-\mathrm{NMR}\left(125 \mathrm{MHz}, \mathrm{CDCl}_{3}\right) \delta 172.97,135.94,133.83,130.09,127.75$, 86.47, 78.70, 55.98, 33.99, 32.80, 30.38, 29.82, 27.34, 22.57, 21.38, 19.09, 18.05, 15.20; MS (ESI) $347\left[\mathrm{M}+\mathrm{Na}^{+}\right]$; HRMS (FAB) calcd. for $\mathrm{C}_{19} \mathrm{H}_{32} \mathrm{O}_{4} \mathrm{Na}\left[\mathrm{M}+\mathrm{Na}^{+}\right]$347.2198, found 347.2187.

(R)-Isopropyl Macrolactone 68: Preparation performed exactly as for $(S)$-isopropyl macrolactone 65, affording $(R)$-isopropyl macrolactone 68 in $66 \%$ yield. $[\alpha]_{\mathrm{D}}+21.3^{\circ}(c 0.09$, $\mathrm{CHCl}_{3}$ ); IR (neat) 3499, 2967, 2926, 2866, 1729, 1453, 1383, 1257, 1111; ${ }^{1} \mathrm{H}-\mathrm{NMR}$ (500 MHz, $\left.\mathrm{CDCl}_{3}\right) \delta 5.65(\operatorname{app~dt}, J=15.5,7.5,1 \mathrm{H}), 5.58(\mathrm{dd}, J=10.7,1.3,1 \mathrm{H}), 5.35(\mathrm{dd}, J=15.5,6.0$, $1 \mathrm{H}), 4.87(\mathrm{~d}, J=7.6,1 \mathrm{H}), 3.49(\mathrm{dd}, J=9.1,6.0,1 \mathrm{H}), 3.34$ (s, 3H), 3.27 (br d, $J=8.8,1 \mathrm{H}), 3.13-$ 3.07 (m, 1H), 2.86 (br s, 1H), 2.34-2.15 (m, 4H), 2.06-1.99 (m, 1H), 1.76 (d, J=1.6, 3H), 1.75$1.58(\mathrm{~m}, 3 \mathrm{H}), 1.47-1.41(\mathrm{~m}, 1 \mathrm{H}), 0.98(\mathrm{~d}, J=7.0,3 \mathrm{H}), 0.93(\mathrm{~d}, J=6.7,3 \mathrm{H}), 0.92(\mathrm{~d}, J=6.7,3 \mathrm{H})$;

${ }^{13} \mathrm{C}-\mathrm{NMR}\left(125 \mathrm{MHz}, \mathrm{CDCl}_{3}\right) \delta 172.50,132.45,132.08,131.58,128.26,82.45,80.74,77.44$, 56.67, 33.00, 32.66, 31.76, 30.56, 25.57, 24.91, 22.44, 19.02, 18.96, 13.20; MS (ESI) 347 $\left[\mathrm{M}+\mathrm{Na}^{+}\right]$; HRMS (FAB) calcd. for $\mathrm{C}_{19} \mathrm{H}_{32} \mathrm{O}_{4} \mathrm{Na}\left[\mathrm{M}+\mathrm{Na}^{+}\right]$347.2198, found 347.2196.

Macrocyclic Secondary Alcohol 69 (diastereomeric mixture): To a solution of macroketone 60 (4 mg, $0.014 \mathrm{mmol})$ in $\mathrm{MeOH}(0.3 \mathrm{~mL})$ at $\mathrm{rt}$ was added $\mathrm{NaBH}_{4}(2 \mathrm{mg}, 0.042 \mathrm{mmol}$ ). After stirring for $5 \mathrm{~min}$, the reaction mixture was carefully treated with $1 \mathrm{M} \mathrm{HCl}(1 \mathrm{~mL})$ and stirring was continued for another $20 \mathrm{~min}$. Then the reaction mixture was diluted with EtOAc, the organic layer was separated, and the aqueous layer was extracted with EtOAc (4x). The combined organic layers were dried $\left(\mathrm{MgSO}_{4}\right)$ and concentrated under reduced pressure to afford 
a diastereomeric mixture of macrocyclic secondary alcohol $69(4 \mathrm{mg}, 95 \%)$ as a colorless oil. IR (neat) $3405,2931,2922,2856,1446,1380,1106,1090 ;{ }^{1} \mathrm{H}-\mathrm{NMR}\left(500 \mathrm{MHz}, \mathrm{CDCl}_{3}\right) \delta 5.66-5.59$ (m, 2H), 5.32 (app t, $J=8.4,2 \mathrm{H}), 5.27-5.19(\mathrm{~m}, 2 \mathrm{H}), 3.83-3.72(\mathrm{~m}, 2 \mathrm{H}), 3.49(\mathrm{~s}, 1 \mathrm{H}), 3.46-3.40$ (m, 2H), 3.36 (app t, $J=10.0,1 \mathrm{H}), 3.30(\mathrm{~s}, 6 \mathrm{H}), 2.74(\mathrm{br} \mathrm{s}, 2 \mathrm{H}), 2.59-2.46(\mathrm{~m}, 2 \mathrm{H}), 2.31-2.26(\mathrm{~m}$, $2 \mathrm{H}), 2.19-2.06(\mathrm{~m}, 2 \mathrm{H}), 2.02-1.90(\mathrm{~m}, 2 \mathrm{H}), 1.83-1.72(\mathrm{~m}, 4 \mathrm{H}), 1.70(\mathrm{~s}, 6 \mathrm{H}), 1.68-1.13(\mathrm{~m}, 12 \mathrm{H})$, 0.94 (app t, $J=6.3,6 \mathrm{H}$ ); ${ }^{13} \mathrm{C}-\mathrm{NMR}\left(125 \mathrm{MHz}, \mathrm{CDCl}_{3}\right) \delta 136.43,136.22,134.53,134.21,129.52$, $129.40,129.28,129.19,84.38,84.14,77.51,77.42,71.17,70.66,56.28,56.22,33.36,33.30$, $32.87,32.50,32.21,32.16,30.47,30.34,26.93,26.91,26.83,25.50,23.46,23.37,21.90,19.67$, 12.58, 12.44; MS (ESI) $305\left[\mathrm{M}+\mathrm{Na}^{+}\right]$; HRMS (FAB) calcd. for $\mathrm{C}_{17} \mathrm{H}_{30} \mathrm{O}_{3} \mathrm{Na}\left[\mathrm{M}+\mathrm{Na}^{+}\right]$305.2093, found 305.2103 .

Macrocyclic Tertiary Alcohol 70 (diastereomeric mixture): To a solution of macroketone $\mathbf{6 0}$ (5.5 mg, $0.020 \mathrm{mmol})$ in THF $(0.4 \mathrm{~mL})$ at $0{ }^{\circ} \mathrm{C}$ was added $\mathrm{MeMgBr}(66 \mu \mathrm{L}, 0.200 \mathrm{mmol}, 3 \mathrm{M}$ in $\mathrm{Et}_{2} \mathrm{O}$ ). After stirring for $5 \mathrm{~min}$, the reaction mixture was treated with saturated aqueous $\mathrm{NH}_{4} \mathrm{Cl}$ solution and diluted with EtOAc. The organic layer was separated and the aqueous layer was extracted with EtOAc (4x). The combined organic layers were dried $\left(\mathrm{MgSO}_{4}\right)$ and concentrated under reduced pressure to afford a diastereomeric mixture of macrocyclic tertiary alcohol 70 (6.0 mg, 95\%) as a colorless oil. IR (neat) 3434, 2933, 2856, 1460, 1448, 1117, 1083; ${ }^{1} \mathrm{H}-\mathrm{NMR}$ (500 $\left.\mathrm{MHz}, \mathrm{CDCl}_{3}\right) \delta 5.66-5.60(\mathrm{~m}, 2 \mathrm{H}), 5.34-5.31(\mathrm{~m}, 2 \mathrm{H}), 5.24-5.17(\mathrm{~m}, 2 \mathrm{H}), 3.46-3.32(\mathrm{~m}, 6 \mathrm{H})$, 3.30 (s, 6H), 2.80-2.70 (m, 2H), 2.61-2.51 (m, 2H), 2.30-2.26 (m, 2H), 2.17 (br s, 1H), 2.14-2.01 $(\mathrm{m}, 2 \mathrm{H}), 1.95-1.82(\mathrm{~m}, 2 \mathrm{H}), 1.77-1.60(\mathrm{~m}, 2 \mathrm{H}), 1.70(\mathrm{~s}, 6 \mathrm{H}), 1.58-1.36(\mathrm{~m}, 8 \mathrm{H}), 1.34-1.14(\mathrm{~m}$, $5 \mathrm{H}), 1.20(\mathrm{~s}, 6 \mathrm{H}), 1.02($ app t, $J=7.2,2 \mathrm{H}), 0.94-0.92(\mathrm{~m}, 6 \mathrm{H}) ;{ }^{13} \mathrm{C}-\mathrm{NMR}\left(125 \mathrm{MHz}, \mathrm{CDCl}_{3}\right) \delta$ $136.55,136.44,134.45,134.35,129.44,129.32,84.34,84.24,72.90,72.80,56.27,56.23,38.71$, $38.60,38.48,38.43,32.10,32.09,30.92,30.56,29.69,29.32,29.24,27.41,27.37,26.79,24.27$, 23.34, 23.33, 21.91, 21.14, 12.64, 12.57; MS (ESI) 319 [M+Na ${ }^{+}$; HRMS (FAB) calcd. for $\mathrm{C}_{18} \mathrm{H}_{32} \mathrm{O}_{3} \mathrm{Na}\left[\mathrm{M}+\mathrm{Na}^{+}\right]$319.2249, found 319.2264.

Macrocyclic $\mathbf{C F}_{3}$-Alcohol 71 (major): To a solution of macroketone $\mathbf{6 0}$ (10 $\mathrm{mg}, 0.036 \mathrm{mmol}$ ) and $\mathrm{TMSCF}_{3}(27 \mu \mathrm{L}, 0.180 \mathrm{mmol})$ in THF $(0.6 \mathrm{~mL})$ at $\mathrm{rt}$ was added a catalytic amount of TBAF. After stirring for $1 \mathrm{~h}$, the reaction mixture was treated with excess TBAF and stirred for another 5 h. The reaction mixture was concentrated under reduced pressure. Purification of the crude product by FC (hexane/EtOAc 3:1) afforded a diastereomeric mixture of alcohol $71(10 \mathrm{mg}$, $80 \%$ ) as a colorless oil. Further purification by FC (hexane/EtOAc 7:1 $\rightarrow 3: 1$ ) provided the major isomer 71 in pure form as a colorless oil. IR (neat) 3409, 2963, 2931, 2922, 1457, 1244, 1150, 1112; ${ }^{1} \mathrm{H}-\mathrm{NMR}\left(500 \mathrm{MHz}, \mathrm{CDCl}_{3}\right) \delta 5.64$ (ddd, $\left.J=17.2,9.4,5.1,1 \mathrm{H}\right), 5.34$ (d, $J=10.7$, $1 \mathrm{H}), 5.19(\mathrm{dd}, J=17.2,8.2,1 \mathrm{H}), 3.43($ app t, $J=9.0,1 \mathrm{H}), 3.36(\operatorname{app} \mathrm{d}, J=9.5,1 \mathrm{H}), 3.30(\mathrm{~s}, 3 \mathrm{H})$, 
2.87 (br s, 1H), 2.56-2.47 (m, 1H), 2.31-2.26 (m, 1H), 2.11-2.03 (m, 1H), 2.00-1.84 (m, 2H), $1.71-1.68(\mathrm{~m}, 2 \mathrm{H}), 1.69(\mathrm{~s}, 3 \mathrm{H}), 1.69-1.38(\mathrm{~m}, 4 \mathrm{H}), 1.30-1.22(\mathrm{~m}, 2 \mathrm{H}), 0.99(\operatorname{app~t}, J=7.3,1 \mathrm{H})$, $0.93(\mathrm{~d}, J=7.0,3 \mathrm{H}) ;{ }^{13} \mathrm{C}-\mathrm{NMR}\left(125 \mathrm{MHz}, \mathrm{CDCl}_{3}\right) \delta 136.38,133.31,129.78,129.45,83.77$, 56.33, 32.00, 31.02, 30.41, 29.72, 26.99, 25.09, 23.93, 23.27, 20.20, 19.63, 12.74; MS (ESI) 373 $\left[\mathrm{M}+\mathrm{Na}^{+}\right]$; HRMS (FAB) calcd. for $\mathrm{C}_{18} \mathrm{H}_{29} \mathrm{~F}_{3} \mathrm{O}_{3} \mathrm{Na}\left[\mathrm{M}+\mathrm{Na}^{+}\right] 373.1966$, found 373.1971.

Macrooxime 72 (diastereomeric mixture): A solution of macroketone 60 (5 $\mathrm{mg}, 0.018 \mathrm{mmol}$ ) and $\mathrm{NH}_{2} \mathrm{OH} \cdot \mathrm{HCl}(12 \mathrm{mg}, 0.178 \mathrm{mmol})$ in pyridine $(0.3 \mathrm{~mL})$ was heated to $45{ }^{\circ} \mathrm{C}$ for $3 \mathrm{~h}$. The reaction mixture was concentrated under reduced pressure and the crude product was purified by FC (hexane/EtOAc 1:1) to afford a diastereomeric mixture of macrooxime 72 (4 $\mathrm{mg}, 70 \%)$ as a colorless oil. IR (neat) 3326, 2930, 1447, 1109, 1086, 981; ${ }^{1} \mathrm{H}-\mathrm{NMR}\left(500 \mathrm{MHz}, \mathrm{CDCl}_{3}\right) \delta 5.72-$ $5.64(\mathrm{~m}, 2 \mathrm{H}), 5.37(\mathrm{~d}, J=9.1,2 \mathrm{H}), 5.31-5.25(\mathrm{~m}, 2 \mathrm{H}), 3.50-3.45(\mathrm{~m}, 2 \mathrm{H}), 3.38-3.35(\mathrm{~m}, 2 \mathrm{H})$, 3.32 (s, 6H), 2.82 (br s, 2H), 2.62-2.57 (m, 2H), 2.43-2.36 (m, 2H), 2.29-2.04 (m, 14H), $1.76(\mathrm{~d}, J$ $=1.6,3 \mathrm{H}), 1.71(\mathrm{~d}, J=1.8,3 \mathrm{H}), 1.56-1.48(\mathrm{~m}, 6 \mathrm{H}), 1.27-1.24(\mathrm{~m}, 2 \mathrm{H}), 0.97(\mathrm{~d}, J=6.8,3 \mathrm{H}), 0.96$ $(\mathrm{d}, J=6.8,3 \mathrm{H}) ;{ }^{13} \mathrm{C}-\mathrm{NMR}\left(125 \mathrm{MHz}, \mathrm{CDCl}_{3}\right) \delta 161.91,161.66,135.46,135.30,134.03,133.76$, $129.76,129.64,129.29,129.19,83.93,83.89,77.65,77.48,56.42,33.66,32.57,32.51,32.42$, $30.62,30.41,30.29,28.22,27.01,26.94,26.70,26.64,24.42,23.51,23.13,12.67$; MS (ESI) 318 $\left[\mathrm{M}+\mathrm{Na}^{+}\right]$; HRMS (FAB) calcd. for $\mathrm{C}_{17} \mathrm{H}_{29} \mathrm{NO}_{3} \mathrm{Na}\left[\mathrm{M}+\mathrm{Na}^{+}\right]$318.2045, found 318.2049.

Biotinylated Macrohydrazone 73 (diastereomeric mixture): A solution of macroketone 60 (6 $\mathrm{mg}, 0.021 \mathrm{mmol})$ and biotin- $\mathrm{dPEG}_{4}$-hydrazide $(13 \mathrm{mg}, 0.026 \mathrm{mmol})$ in $\mathrm{EtOH}(0.3 \mathrm{~mL})$ was heated to $55^{\circ} \mathrm{C}$ for $1 \mathrm{~h}$. The reaction mixture was concentrated under reduced pressure and the crude product was purified by $\mathrm{FC}\left(\mathrm{CH}_{2} \mathrm{Cl}_{2} / \mathrm{MeOH} 4: 1\right)$ to afford a diastereomeric mixture of biotinylated macrohydrazone 73 (12 mg, 75\%) as a colorless oil. IR (neat) 3291, 2930, 2872, 1703, 1691, 1680, 1668, 1540, 1459, 1261, 1104; ${ }^{1} \mathrm{H}-\mathrm{NMR}\left(500 \mathrm{MHz}, \mathrm{CDCl}_{3}\right) \delta 9.56(\mathrm{~s}, 0.4 \mathrm{H})$, $9.50(\mathrm{~s}, 0.4 \mathrm{H}), 9.23(\mathrm{~s}, 0.6 \mathrm{H}), 9.10(\mathrm{~s}, 0.6 \mathrm{H}), 6.77-6.73(\mathrm{~m}, 2 \mathrm{H}), 6.58(\mathrm{~s}, 0.6 \mathrm{H}), 6.50(\mathrm{~s}, 6 \mathrm{H}), 6.12$ $(\mathrm{s}, 0.4 \mathrm{H}), 6.08(\mathrm{~s}, 0.4 \mathrm{H}), 5.70-5.63(\mathrm{~m}, 2 \mathrm{H}), 5.42-5.34(\mathrm{~m}, 2 \mathrm{H}), 5.32-5.25(\mathrm{~m}, 2 \mathrm{H}), 5.18(\mathrm{~s}, 0.8 \mathrm{H})$, $5.04(\mathrm{~s}, 1.2 \mathrm{H}), 4.50-4.47(\mathrm{~m}, 2 \mathrm{H}), 4.37-4.32(\mathrm{~m}, 2 \mathrm{H}), 3.83-3.79(\mathrm{~m}, 4 \mathrm{H}), 3.68-3.55(\mathrm{~m}, 32 \mathrm{H})$, 3.48-3.41 (m, 6H), 3.39-3.28 (m, 8H), 3.16-3.14 (m, 2H), 2.97-2.89 (m, 5H), $2.82(\mathrm{~s}, 0.6 \mathrm{H}), 2.78$ $(\mathrm{s}, 0.4 \mathrm{H}), 2.74-2.70(\mathrm{~m}, 2 \mathrm{H}), 2.64-2.56(\mathrm{~m}, 4 \mathrm{H}), 2.30-2.22(\mathrm{~m}, 10 \mathrm{H}), 2.20-2.02(\mathrm{~m}, 4 \mathrm{H}), 2.17(\mathrm{~s}$, $3 \mathrm{H}), 1.77(\mathrm{~s}, 3 \mathrm{H}), 1.75-1.64(\mathrm{~m}, 12 \mathrm{H}), 1.25-1.24(\mathrm{~m}, 2 \mathrm{H}), 0.95(\mathrm{~d}, J=7.0,3.6 \mathrm{H}), 0.92(\mathrm{~d}, J=6.6$, 2.4H); ${ }^{13} \mathrm{C}-\mathrm{NMR}\left(125 \mathrm{MHz}, \mathrm{CDCl}_{3}\right) \delta 173.95,173.74,173.33,173.22,163.73,163.67,163.49$, $160.94,160.65,156.08,155.65,135.39,135.02$, 134.78, 133.92, 133.65, 132.80, 132.62, 130.73, $130.61,129.71,129.56,129.39,128.99,128.92,83.99,83.83,83.79,83.70,77.64,77.53,77.46$, $77.41,70.42$, 70.38, 70.14, 70.04, 69.92, 61.77, 61.73, 60.08, 56.46, 56.40, 40.61, 40.54, 39.13, $39.10,36.29,35.86,35.77,33.17,32.68,32.44,30.92$, 30.67, 30.46, 30.36, 29.68, 28.07, 27.41, 
26.88, 26.81, 26.58, 25.51, 25.45, 24.59, 23.63, 23.49, 23.26, 12.71, 12.66; MS (ESI) 768 $\left[\mathrm{M}+\mathrm{H}^{+}\right]$; HRMS (FAB) calcd. for $\mathrm{C}_{38} \mathrm{H}_{66} \mathrm{~N}_{5} \mathrm{O}_{9} \mathrm{~S}\left[\mathrm{M}+\mathrm{H}^{+}\right]$768.4581, found 768.4581.

\section{Materials and methods for mouse breast tumor cell and HUVEC cell studies:}

Chamber Cell Migration Assay (Tables 1 and 3): Cell migrations were assayed with Boyden chambers $[8.0 \mu \mathrm{m}$ pore size, polyethylene terephthalate membrane, FALCON cell culture insert (Becton-Dickinson)]. 4T1 mouse breast tumor cells or HUVECs were trypsinized and counted. $300 \mu \mathrm{l}$ of $5-10 \times 10^{4}$ cells in serum-free medium was added to the upper chamber and $500 \mu \mathrm{l}$ of medium with $10 \%$ fetal bovine serum (FBS) was added to the lower chamber. The transwells were incubated for $6-8 \mathrm{~h}$ at $37{ }^{\circ} \mathrm{C}$ with different concentrations of chemical compound in both upper and lower chamber. Cells on the inside of the transwell inserts were removed with a cotton swab, and cells on the underside of the insert were fixed and stained. Photographs of three random regions were taken and the number of cells was counted to calculate the average number of cells that have transmigrated.

As an example, the outcome of the 4T1 tumor cell migration assay with macrolactone $\mathbf{4 8}$ and migrastatin $\mathbf{1}$ is shown below.
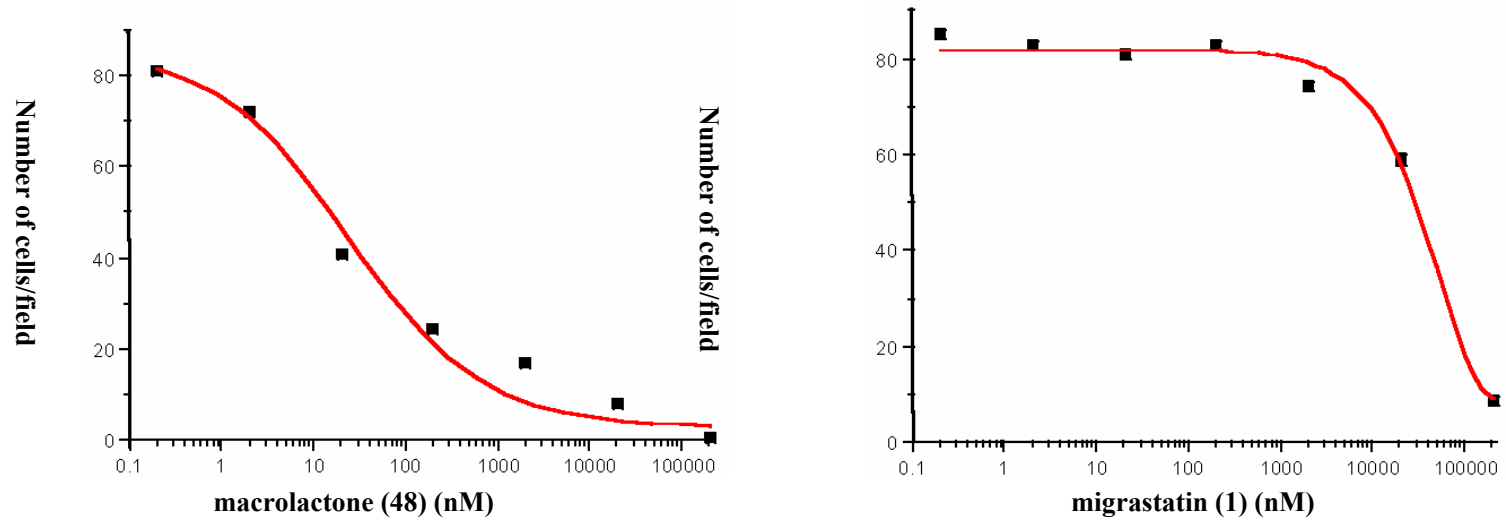

Mouse Plasma Stability Studies (Table 2): HPLC conditions: The sample was injected and separated using an Inertsil ODS3 6u 3x $150 \mathrm{~mm}$ column with a mobile phase of MeCN and water (50\% for migrastatin) at a flow of $0.4 \mathrm{~mL} / \mathrm{min}$, monitored at $220 \mathrm{~nm}$ at 0.02 AUFS (the retention time for migrastatin is ca. $4 \mathrm{~min}$, the identity of this peak was confirmed by mass spectral 
analysis). Incubation and sample preparation conditions: A solution (ca. $30 \mathrm{mM}$ ) of chemical compound (Table 2) in DMSO was prepared. $2 \mu \mathrm{L}$ of the solution was added to a mixture containing $200 \mu \mathrm{L}$ of mouse plasma and $800 \mu \mathrm{L}$ of PBS. The resulting solution was put into a water bath at $37^{\circ} \mathrm{C}$, and $100 \mu \mathrm{L}$ of sample was withdrawn at 10, 20, 30, 45, and $60 \mathrm{~min}$. The precipitate was removed by centrifugation and $20 \mu \mathrm{L}$ of the supernatant was injected onto the HPLC.

Cell Proliferation Assay: 4x 104 of 4T1 tumor cells in RPMI-1640 medium containing 10\% FBS were seeded into wells of 96-multiwell plates (Becton-Dickinson) in the presence or absence of chemical compounds and then incubated at $37{ }^{\circ} \mathrm{C}$ for $48 \mathrm{~h}$. An MTT kit (Cell Proliferation Kit I, Roche) (a colorimetric assay) was used to quantify cell proliferation and viability. The number of living cells, thus the total metabolic activity, directly correlates to the amount of purple formazan crystals formed (monitored by the absorbance).

The outcome of the 4T1 tumor cell proliferation assay with migrastatin $\mathbf{1}$, macrolactone $\mathbf{4 8}$, macrolactam 55, macroketone 60 is shown below.

\section{Effects of chemical compounds on 4T1 cell proliferation}

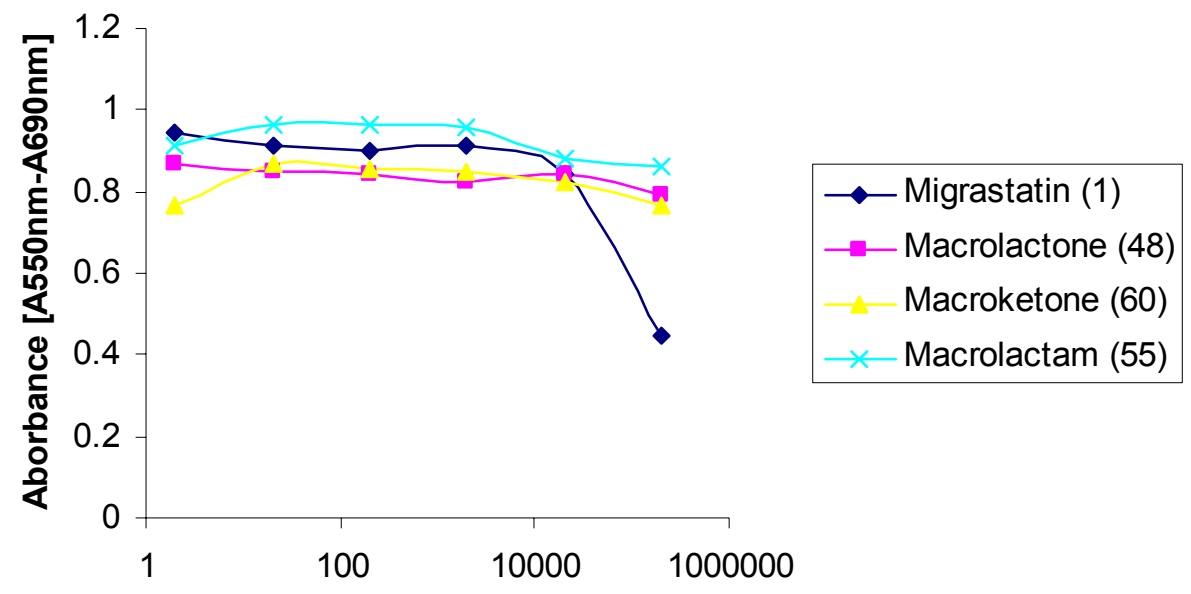

Conc. of compounds (nM) 


\section{Materials and methods for human cancer cell studies:}

Cell culture: The human ovarian cancer cell lines Ovcar3 and IGROV were grown in M5 media. The colon cell lines HT 29 and HCT 116 were cultivated in DMEM containing 10\% FCS in a humidified environment at $37^{\circ} \mathrm{C}$. Myeloma cell lines CAG (obtained from The Myeloma Institute for Research and Therapy, University of Arkansas) and RPMI8226 as well as lymphoma cell line RL were maintained at RPMI1640 medium containing 10\% FCS. All cell lines were acquired from the ATCC if not otherwise stated.

Migration Assays. Cell migrations were assayed with $8 \mu \mathrm{m}$ of microporous $6.5-\mathrm{mm}$ transwell plates (Corning). $200 \mu 1$ of $2 \times 10^{5}$ cells in serum-free RPMI 1640 medium containing $0.5 \%$ BSA were added to the upper chamber and $600 \mu$ of medium with $10 \%$ fetal bovine serum was added to the lower chamber. Transwells were incubated for 6 hours at $37^{\circ} \mathrm{C}$ for liquid tumor cells (RL, RPMI8226 and CAG) and for 12 hours for solid tumors (HT29, HCT 116, IGROV and Ovcar3) with following concentrations of chemical compounds in both upper and lower chambers (2,3dihydro-migrastatin core (48): $240 \mathrm{nM}$, migrastatin lactam (55): 2,550nM, migrastatin ketone (60): $1,000 \mathrm{nM}$ ). Cells migrated to the lower wells were collected and counted for liquid tumors, solid tumors were processed as previously described. ${ }^{28}$ Data shown are representative of at least three experiments.

Wound Healing Assay. The tumor cells were seeded into 24-multiwell plates (BectonDickinson) and cultivated until the cells formed a confluent monolayer. Wounds were set by horizontally scratching the monolayer with a sterile pipette tip. The cells were thereafter washed twice with Phosphate Buffered Saline (PBS) to remove detached cells. Growth media was then added containing different concentrations of the chemical compound and incubated at $37^{\circ} \mathrm{C}(2,3-$ dihydro-migrastatin core (48): 240 and 2,400nM, migrastatin lactam (55): 2,550 and 25,500nM, migrastatin ketone (60): 1,000 and 10,000nM). The cells were photographed at the beginning of the experiment and after 24 and $48 \mathrm{~h}$ to assess the progression of cell migration into the wound.

Cell proliferation assay. $5 \times 10^{3} \mathrm{CAG}$ cells were plated into wells of 96 multi-well plates (Becton-Dickinson) using RPMI with 10\% FCS (Sigma) as growth media in the presence or absence of chemical compounds and then incubated at $37^{\circ} \mathrm{C}$ for 72 hours. In the last 20 hours, 
sodium 3'-[1-(phenylamino-carbonyl)-3,4-tetrazolium]-bis (4-methoxy-6-nitro) benzene sulfonic acid hydrate (XTT) was added and optical absorbance at $490 \mathrm{~nm}$ were measured. As reference wavelength $650 \mathrm{~nm}$ was used. The number of living cells, thus the total metabolic activity, directly correlates to the amount of orange formazan formed. The result was expressed as percentage of the control.

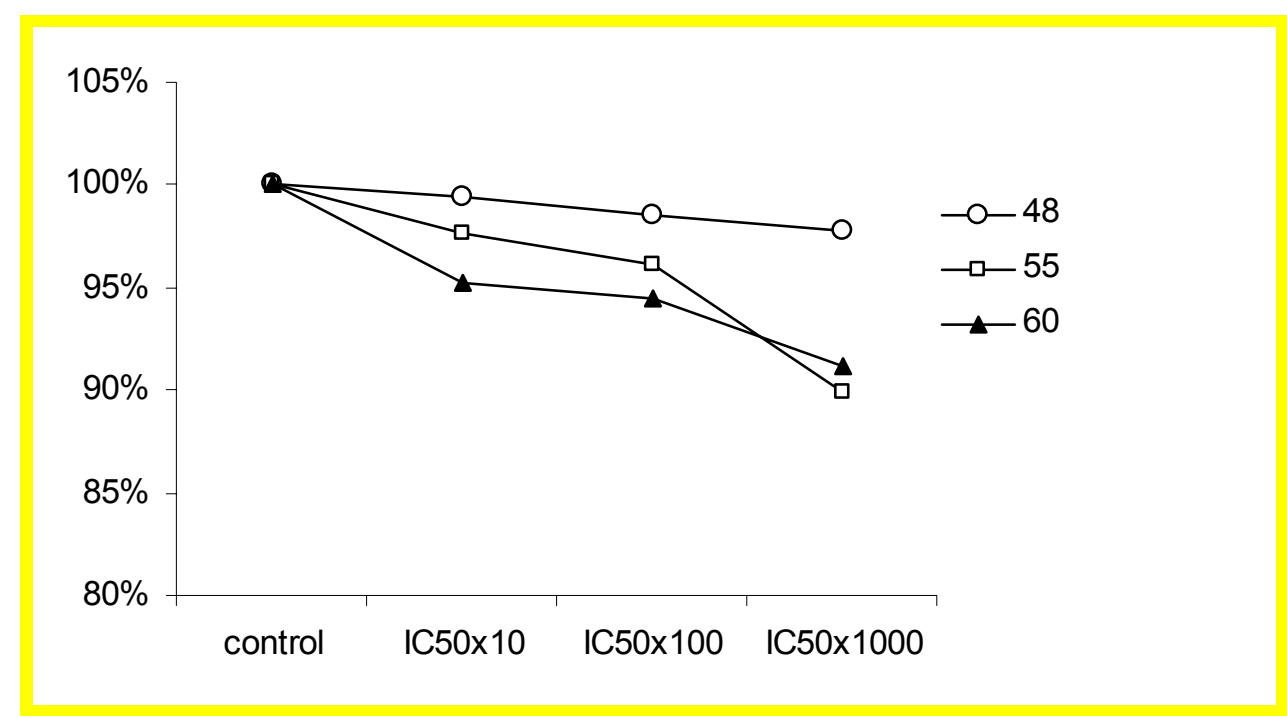

$\mathrm{IC}_{50}$ : DMC (48) $=24 \mathrm{nM}$, macroketone $(\mathbf{5 5})=100 \mathrm{nM}$ and macrolactam $(\mathbf{6 0})=255 \mathrm{nM}$. 